\title{
Infrared signature studies of aerospace vehicles
}

\author{
Shripad P. Mahulikar*, Hemant R. Sonawane, G. Arvind Rao \\ Department of Aerospace Engineering, Indian Institute of Technology—Bombay, P.O. IIT Powai, Mumbai 400076, India
}

\begin{abstract}
Infrared (IR) emissions from aircraft are used to detect, track, and lock-on to the target. MAN Portable Air Defence Systems (MANPADS) have emerged as a major cause of aircraft and helicopter loss. Therefore, IR signature studies are important to counter this threat for survivability enhancement, and are an important aspect of stealth technology. This paper reviews contemporary developments in this discipline, with particular emphasis on IR signature prediction from aerospace vehicles. The role of atmosphere in IR signature analysis, and relation between IR signature level and target susceptibility are illustrated. Also, IR signature suppression systems and countermeasure techniques are discussed, to highlight their effectiveness and implications in terms of penalties.
\end{abstract}

Keywords: Electro-optical warfare; IR countermeasures; IR signature; IR suppression; Lethal envelop; Low observables; Stealth; Survivability; Susceptibility

\section{Contents}

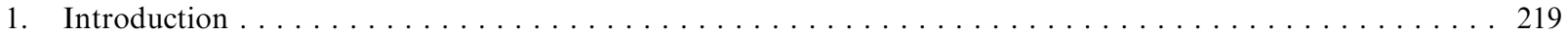

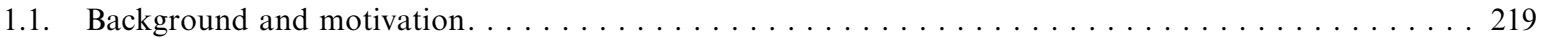

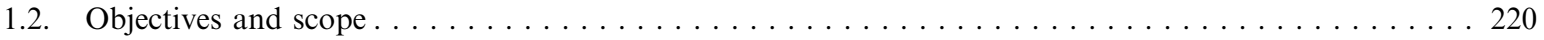

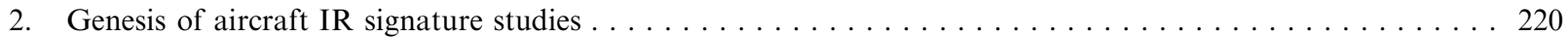

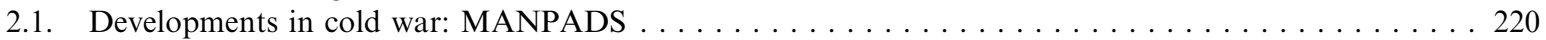

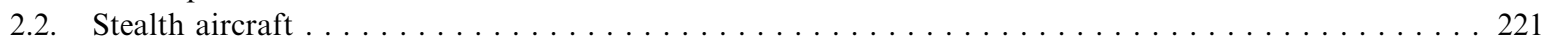

2.3. Recent developments in low observables ........................... 221

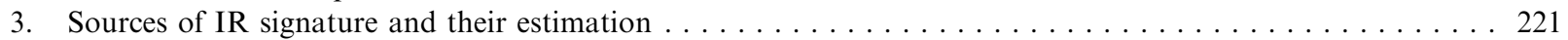

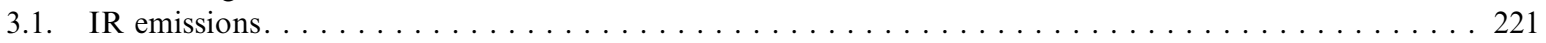

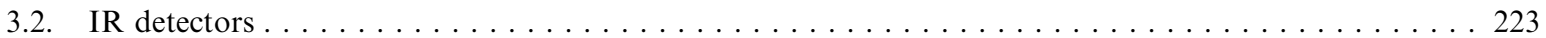

Abbreviations: AAM, air-to-air missile; BHO, Black Hole Ocarina; BPR, bypass ratio; CBT, centre body tailpipe; EOSAS, electrooptical signature evaluation system; IIR, imaging infrared; IR, infrared; IRCM, IR counter-measure; IRSL, IR signature level; IRSS, IR signature suppression; IRST, infrared search and track; IRSTORM, Infrared Seeker Trade-Off Requirements Model; MANPADS, MAN portable air defence systems; MCP, maximum continuous power; NIRATAM, NATO Infra-Red Air Target Model; OGE, out-of-ground effect; PRISM, Physically Reasonable Infrared Signature Model; RADAR, radio detection and ranging; RCS, radar cross-section; SAM, surface-to-air missile; SIRRM, Standardized Infrared Radiation Model; SPIRITS, spectral infrared imaging of targets and scenes; TFE, turbo-fan engine; TJE, turbo-jet engine; WW, World War 
3.3. Atmospheric transmission of IR and estimation of atmospheric IR-radiance . . . . . . . . . . . . 224

3.3.1. Estimation of atmospheric transmission of IR using LOWTRAN code . . . . . . . . . . . . 225

3.3.2. Estimation of atmospheric IR-radiance using Berger's model . . . . . . . . . . . . . 225

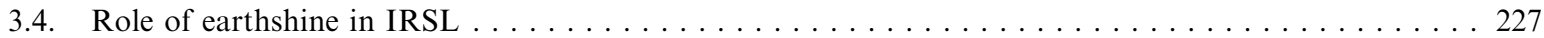

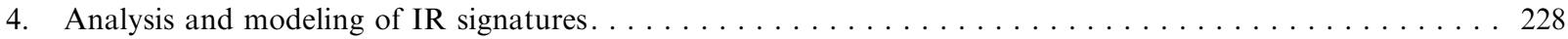

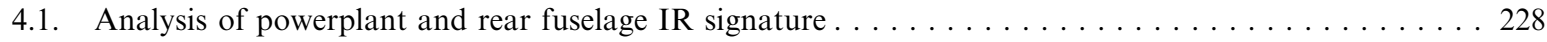

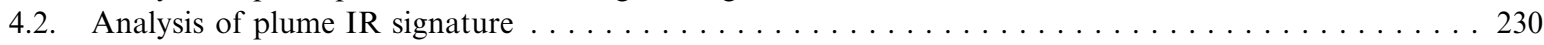

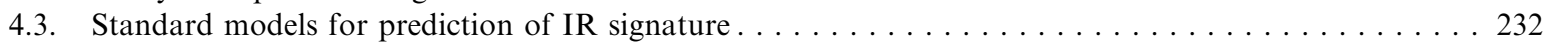

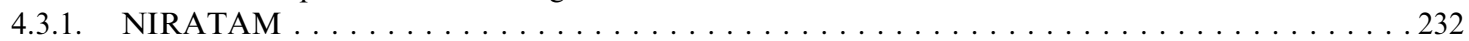

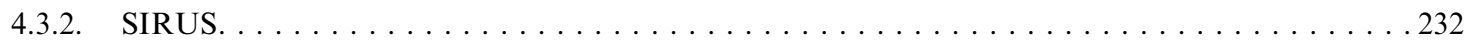

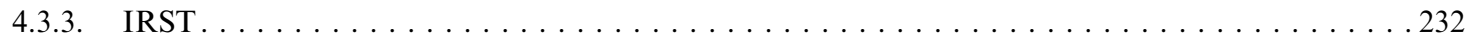

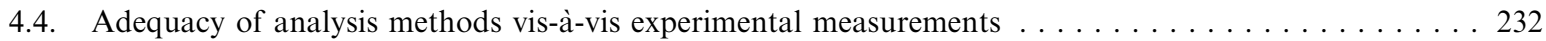

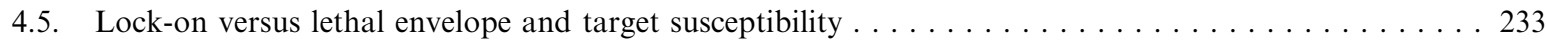

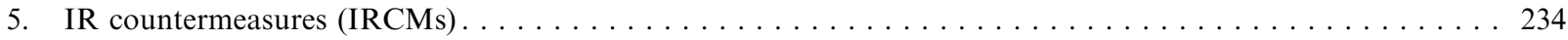

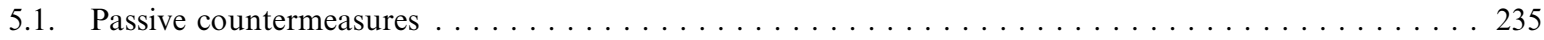

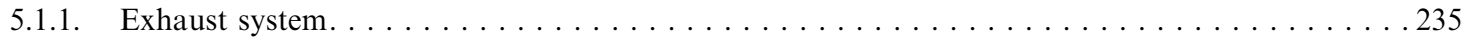

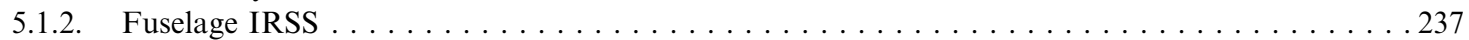

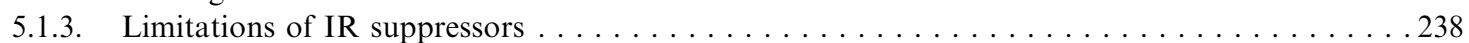

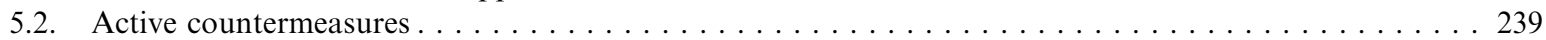

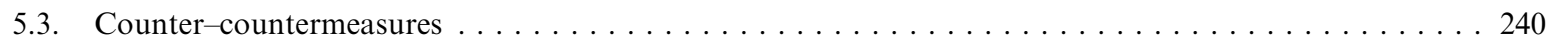

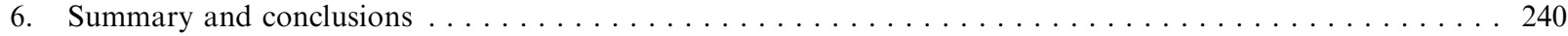

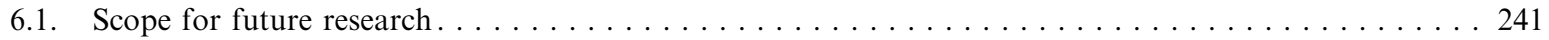

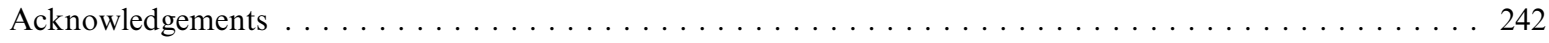

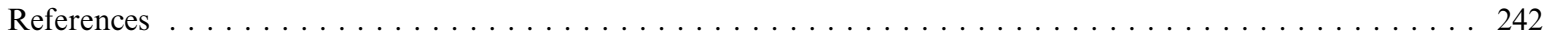

\section{Introduction}

Wars are increasingly driven by technology, and the aim is to use airpower extensively to gain early superiority, as this ensures higher Mission Attainment Measure. Survivability is an important aspect in warfare, because aircraft/helicopters are crucial to mission objectives. Since they are a crucial force in tactical warfare, military forces are constantly engaged in upgrading their fleet, to establish control over the airspace. In this process, they strive for best target detection, and search and tracking systems, to counter their enemy operations. Aircraft/helicopter designers are making them stealthier by reducing their signatures; viz. visual, aural, infrared (IR), and radio detection and ranging (RADAR). But more sensitive signature detection systems are also being concurrently developed, thereby making signature suppression requirements ever more stringent.

Majority of aircraft/helicopters lost in tactical warfare have been destroyed by heat-seeking missiles. Further, passive detection and tracking is tactically superior to active, for comparable detection range. With increasing sensitivities of IRdetectors, analysis of passively emitted IR signatures has emerged as an important component of stealth technology. Availability of portable IRguided missiles to terrorist organizations has further aggravated the problem [1]. Consequently, IR signature analysis is important for assessing aircraft/helicopter susceptibility.

\subsection{Background and motivation}

The following statistics have forced the aerospace community to incorporate IR signature considerations in design and operation of aerospace vehicles:

- Since 1967, IR guidance has been effectively used by MAN Portable Air Defence Systems (MANPADS) in all major wars and conflicts. These wars include South East Asian conflict (19631973), Yom Kippur war (1973), Soviet-Afghanistan conflict (1986), and Gulf war (1991).

- Over 40 civilian aircraft have been hit by MANPADS since 1970, causing 25 unserviceable crashes [2].

- From 1967 to 1993 , 89\% of all helicopter and aircraft downed were due to IR-guided missiles $[3,4]$. Therefore, it was stated by Powell in Ref. [5]: 'No threat is more serious to aviation than MANPADS'. 


\begin{tabular}{|c|c|c|c|}
\hline \multicolumn{2}{|c|}{ Nomenclature } & $V$ & velocity $(\mathrm{m} / \mathrm{s})$ \\
\hline$A$ & area $\left(\mathrm{m}^{2}\right)$ & & \\
\hline$B$ & $\begin{array}{l}\text { Boltzmann constant } \\
\left(=1.3807 \times 10^{-23} \mathrm{~J} / \mathrm{K}\right)\end{array}$ & \multicolumn{2}{|c|}{ Greek letters } \\
\hline$c$ & $\begin{array}{l}\text { velocity of light in vacuum } \\
\left(=3 \times 10^{8} \mathrm{~m} / \mathrm{s}\right)\end{array}$ & $\varepsilon$ & $\begin{array}{l}\text { emissivity (dimensionless) } \\
\text { viewing aspect (deg, rad) }\end{array}$ \\
\hline$C_{1}, C_{2}$ & coefficients in Eq. (2.1) & $\lambda$ & wavelength $(\mu \mathrm{m})$ \\
\hline$E_{\mathrm{B} \lambda}$ & $\begin{array}{l}\text { monochromatic hemispherical emissive } \\
\text { power of black body }\left(\mathrm{W} / \mu \mathrm{m} \mathrm{m}^{2}\right)\end{array}$ & & $\begin{array}{l}\text { frequency }\left(\mathrm{s}^{-1}\right) \\
\text { solid angle subtended }(\mathrm{Sr})\end{array}$ \\
\hline$H$ & flight altitude $(\mathrm{m})$ & & \\
\hline$H_{\mathrm{atm}}$ & $\begin{array}{l}\text { height of atmosphere that contains IR- } \\
\text { radiation participating gases }(\mathrm{m})\end{array}$ & \multicolumn{2}{|c|}{ Subscripts } \\
\hline$h_{\mathrm{p}}$ & $\begin{array}{l}\text { Planck's constant } \\
\left(=6.626068 \times 10^{-34} \mathrm{~J} \mathrm{~s}\right)\end{array}$ & $\begin{array}{l}\text { ac } \\
\text { dew }\end{array}$ & $\begin{array}{l}\text { aircraft } \\
\text { dew point }\end{array}$ \\
\hline$I$ & directional intensity of emission (W/Sr) & $\mathrm{g}$ & ground \\
\hline$K$ & $\begin{array}{l}\text { ratio of velocity of aircraft to velocity of } \\
\text { missile }\left(V_{\mathrm{ac}} / V_{\mathrm{m}}\right) \text { (dimensionless) }\end{array}$ & $\begin{array}{l}\text { lethal } \\
\mathrm{m}\end{array}$ & $\begin{array}{l}\text { lethal envelop } \\
\text { missile }\end{array}$ \\
\hline$k$ & absorption coefficient (dimensionless) & th & threshold \\
\hline$l$ & length $(\mathrm{m})$ & trans & transition from heating to cooling of rear \\
\hline$M_{\infty}$ & freestream Mach number (dimensionless) & & fuselage skin \\
\hline$R_{\mathrm{e}}$ & radius of earth $(\mathrm{m})$ & $\Delta \lambda$ & spectral interval \\
\hline$R_{\mathrm{LO}}$ & lock-on range $(\mathrm{m})$ & $\lambda$ & spectral quantity \\
\hline$T$ & temperature $(\mathrm{K})$ & 1,2 & without and with $\mathrm{O}_{3}$ emission, respec- \\
\hline$t$ & temperature $\left({ }^{\circ} \mathrm{C}\right)$ & & tively \\
\hline
\end{tabular}

Hitherto, RADAR was primarily used for detection, using the target's radar cross-section (RCS). Due to its active nature and developments in countermeasures, the effectiveness of RADAR for detection and tracking is being challenged. Due to developments in the lethal anti-radiation missiles, RADAR detectors are under threat. Target detection, tracking, and lock-on, by interception of passively emitted IR signatures, are advantageous in tactical warfare. This trend is responsible for the incorporation of IR signature suppression (IRSS) systems and IR countermeasures (IRCMs).

\subsection{Objectives and scope}

This paper reviews studies in IR signatures of aerospace vehicles, for illustrating developments leading to the contemporary understanding. Therefore, it begins with historical developments in IR signature analyses, followed by an overview of prominent IR sources in aircraft/helicopter, and their prediction models. Models for predicting IR transmissivity of the intervening atmosphere and atmospheric radiance of IR are also discussed. Relation between IR signature level (IRSL) and target susceptibility is reviewed, to gauge the effectiveness of IRSS systems.

\section{Genesis of aircraft IR signature studies}

Prior to World War (WW) I, defence establishments in USA, Britain, and Germany developed IR equipment for military applications. These efforts were primarily concentrated on signalling, search, and night vision equipments. In 1937, IR was used for the first time for air-to-air detection [6]; and during WW-II, IR equipments were used for the first time for tracking [6]. After WW-II, the Soviet Union emerged as a major proponent of IR equipments [6]. However, developments in IR-detection were retarded by the initial success of RADAR, which attracted the major funding for development. Therefore, interest in development of IR-detection systems was confined to laboratory research until 1960 [7].

\subsection{Developments in cold war: MANPADS}

After WW-II, USA started the Sidewinder program and USSR also started their anti-aircraft 
missile program. By 1967, these parallel programs led to the development of MANPADS; which are cheap and easy to use, and proliferated world-wide. Several variants of IR-guided surface-to-air missiles (SAMs) and air-to-air missiles (AAMs) were developed for specific applications (Ref. Table 1 for a representative list). The MANPADS proved to be especially lethal against low flying aircraft and helicopters [4]. So far, about one million MANPADS have been manufactured worldwide [2], and approximately 500,000 missiles are in circulation [8].

\subsection{Stealth aircraft}

Till 1970, aircraft survivability as a discipline in aircraft design was not given due importance. A revolution in aircraft design priorities started with the first program to design stealth aircraft, Have Blue $[9,10]$. After mid-1980, aircraft survivability was established as a major discipline, and today, military forces consider survivability enhancement as the foremost design feature. The primary aim of the Have Blue program was to defeat the RADARbased defence systems, but due consideration to aircraft IR signatures was also given [11]. The first aircraft manufactured with stealth capabilities, F-117A, were flown in June 1981 [12]. In the Gulf War, F-117A aircraft constituted only $2-3 \%$ of the total 1900 fighters and bombers, but attacked $40 \%$ of the strategic targets. A single F-117A sortie is equivalent to 95 sorties of aircraft used earlier in the Vietnam War [9].

\subsection{Recent developments in low observables}

For reducing RCS, F-117A, A-12, F/A-22, RA-66 and $\mathrm{B} 2$ have modified the engine inlet and exhaust, have high wing sweep angles, and do not have bumps, bulges, and holes [13]. Technology for

Table 1

Common heat-seeking missiles

Missile Missiles

Type

SAM CHAPARRAL, REDEYE, RAM, STINGER, B/RMP, SA-7, SA-9, SA-13, SA-14, SA-16, SA-18, Tan-Sam

AAM AIM 4D, AIM 9L/M, MICAL, IRIS, Sidewinder, Asraam, AA-2, AA-3, AA-5, AA-6, AA-11, Magic-2, Python-3, CAA-1, CAA-2, Piranha, K-13A reduction of IR emissions from hot engine parts, plume, and fuselage are also being developed by aircraft manufacturers. The atmospheric transmission of IR radiation has been modelled by codes; e.g. LOWTRAN, MODTRAN, HITRAN (which differ in their spectral resolution). In 1998, the US Army initiated the Advanced Threat IR Countermeasures System (ATIRCM) and Directional IR Countermeasures System (DIRCM) for aircraft [14]. The US Military initiated the incorporation of integrated IRCMs on 1047 helicopters, which is expected to be completed in a phased manner by 2014 [15]. The list includes Special Operations Blackhawks, Special Operations Chinooks, Army Apache, Army Blackhawks, Army Chinooks, and Army Kiowa warrior helicopters.

There have been several US patents on IR signature reduction and management-related technologies, which include the following: (i) modification of engine exhaust geometry to enhance mixing of exhaust gases with the atmosphere [16-26], (ii) electrical heating [27], heat pipe cooling [28], liquid evaporative cooling [29], chemical treatment of aircraft skin [30,31], (iii) surface geometry modifications [32], (iv) surface emissivity alteration [30,31,33,34], (v) plume signature tailoring [35], (vi) IRCMs [36], etc.

\section{Sources of IR signature and their estimation}

The discrimination between IR emissions from the target and the surrounding background leads to target detection. Engine hot parts, exhaust plume, rear fuselage, and aerodynamically heated skin, are the important sources of IR emission in an aircraft; as illustrated in Fig. 1(a). The total IR signature [37] of an aircraft can be expressed as [Ref. Fig. 1(b)]: Total signature $=$ aircraft hot parts emission + aircraft plume emission + skin emission + reflected skyshine + reflected earthshine + reflected sunshine.

\subsection{IR emissions}

The IRSL depends on the contrast generated due to the difference between IR radiance (emission and reflection) level of the target and its background. The IR emission of a black body is a function of frequency and absolute temperature, as given by Planck's Law as (Ref. e.g. [6])

$E_{\mathrm{B} \lambda}=\frac{2 \pi h_{\mathrm{p}} v^{3}}{c^{2}\left[\exp \left(h_{\mathrm{p}} v / B T\right)-1\right]}$. 

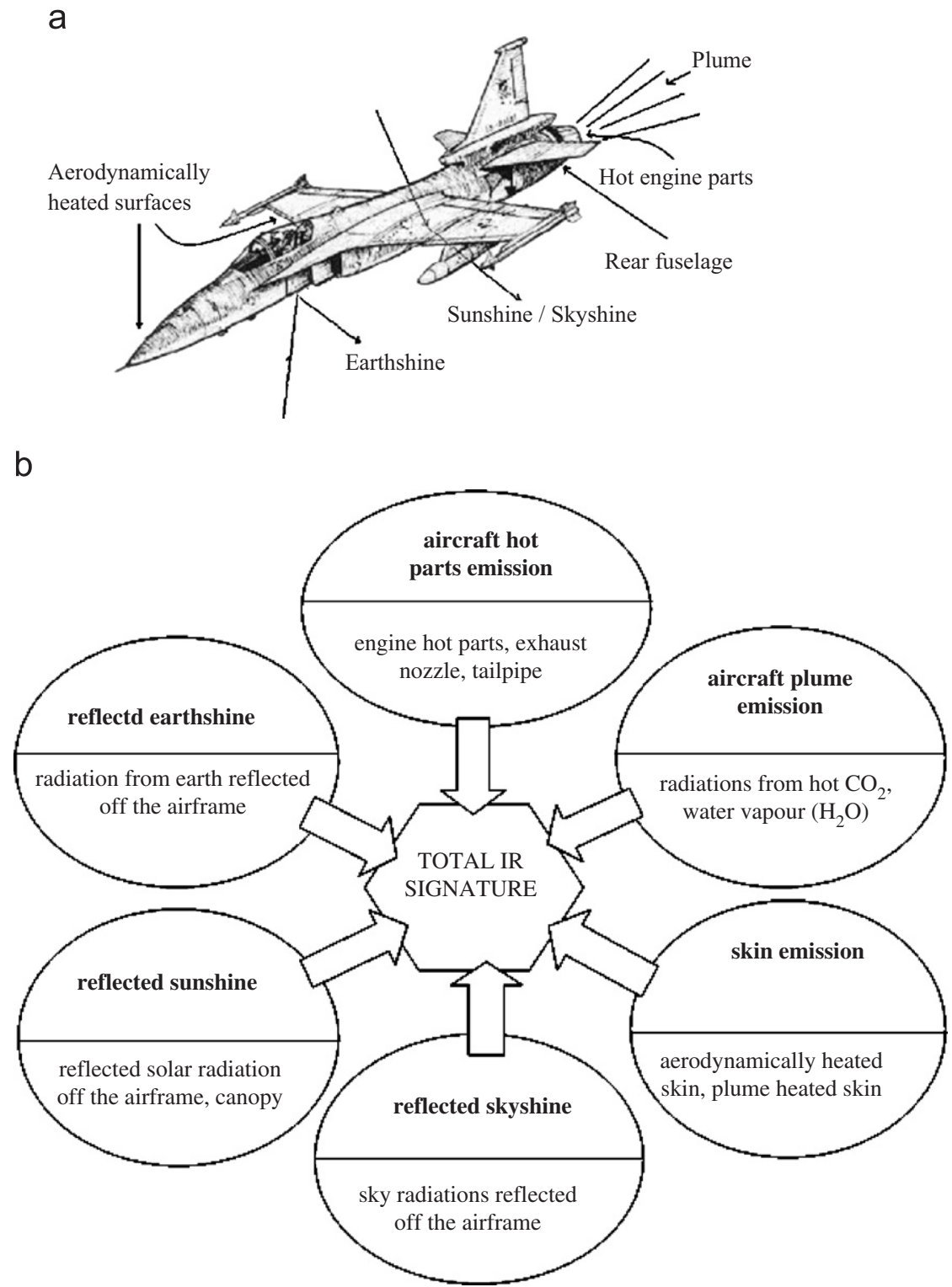

Fig. 1. Sources and details of IR signature of aircraft: (a) sources of IR radiance from typical fighter plane and (b) distribution and details of IR signature of aircraft.

The attenuation of IR radiation in the atmosphere is highly dependent on wavelength of radiation, temperature, and composition of radiation participating gases. The IR spectrum covers the range, $0.77-1000 \mu \mathrm{m}$; i.e. between the visible (red colour) and microwave radiation. However, mainly two atmospheric windows where the transmittance is high, $3-5$ and $8-12 \mu \mathrm{m}$, are used for surveillance and tracking. Outside these windows, attenuation of IR is high, due to the role of $\mathrm{CO}_{2}$ and $\mathrm{H}_{2} \mathrm{O}$ (vap.) in absorption and scattering [38]. At low altitudes or in cloudy weather conditions, atmospheric IR transmittance is generally very poor. At higher altitudes, where $\mathrm{H}_{2} \mathrm{O}$ (vap.) and $\mathrm{CO}_{2}$ concentration is much lower, IR transmission is superior [39]. The 3-5 $\mu \mathrm{m}$ window corresponds to higher peak emission temperature $\left(\sim 450^{\circ} \mathrm{C}\right)$, and is better suited for detecting hot spots. The $8-12 \mu \mathrm{m}$ band has lower peak emission temperature $\left(\sim 17^{\circ} \mathrm{C}\right)$, and is generally used for emissions from larger surfaces at lower temperatures [40].

The intensity of IR-radiation from an aircraft is not uniform in all directions, due to the anisotropic nature of emission from the distributed IR sources 
on the aircraft. When viewed from front and sides, the plume and airframe contribute; and when viewed from the rear, the engine hot parts become the major source of IR radiation. When viewed from the rear, a typical IR-guided SAM can achieve a lock-on from 4-6 km, because of the direct view of hot engine parts at $600-700^{\circ} \mathrm{C}$ [9]. The IR plot of a typical jet-engine-powered aircraft from various view angles is given in Fig. 2(a). In general, an aircraft with a jet engine has an IR radiation intensity in the range $100-1000 \mathrm{~W} / \mathrm{Sr}$, over several viewing aspects [13]. For the same thrust level, turbojets have larger IRSL than turbofans, and turbofans have larger IRSL than turboprops [13]. In helicopters [Ref. Fig. 2(b)], the main contributors of IR signature are: (i) the engine exhaust duct, (ii) the direct view of engine hot parts like the turbine blades, (iii) the tail boom heated by exhaust plume, and (iv) the exhaust plume.

\subsection{IR detectors}

Over the years, significant developments have taken place in IR-detector technology [41], towards increasing their sensitivity [i.e. reducing their Noise Equivalent Irradiance (NEI)]. Current generation

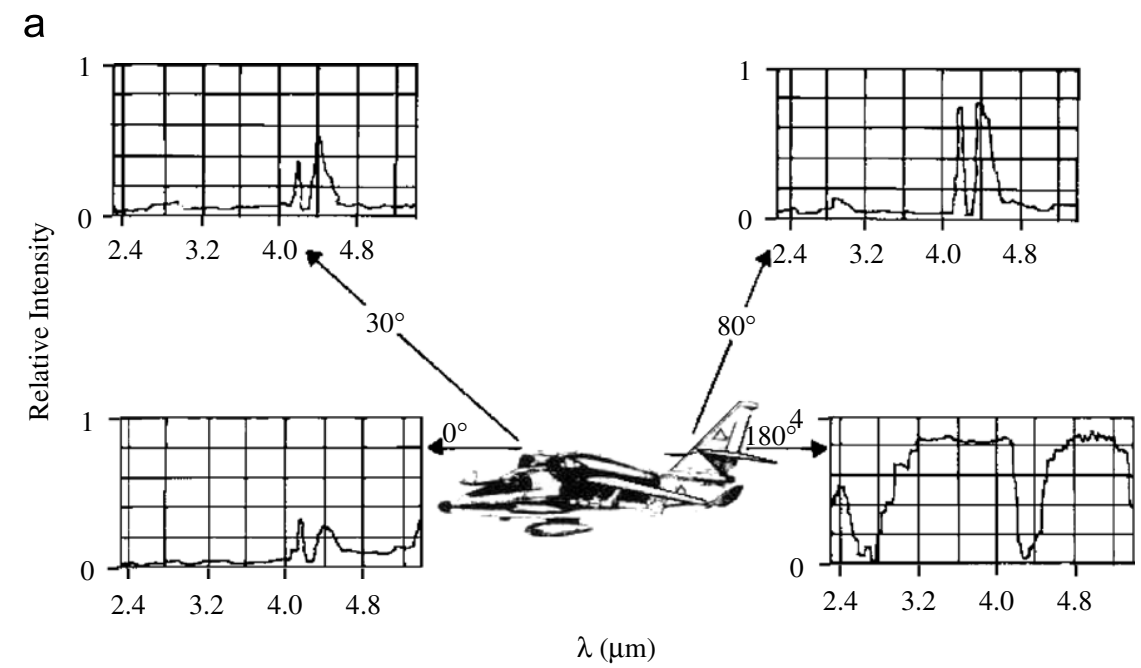

b

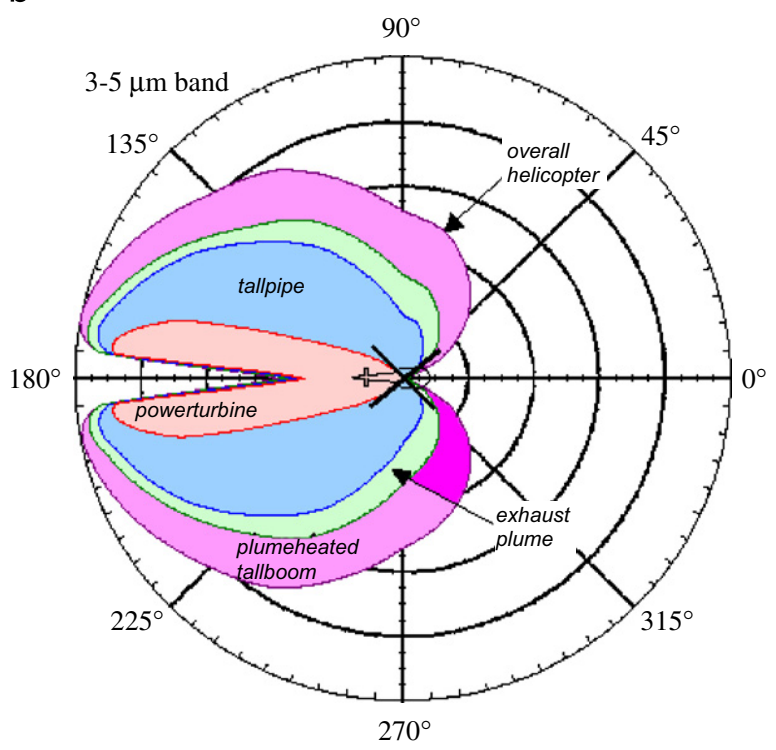

Fig. 2. IR signature variation of gas turbine engine-powered aerospace vehicle: (a) fixed wing aircraft (after [13]) and (b) rotary wing aircraft Bell UH-1H (after [3]). 
missiles use cooled GaAs/AlGaAs (Aluminium Gallium Arsenide) and $\mathrm{HgCdTe}$ (Mercury Cadmium Telluride) detectors. These detectors operate in the mid-wave $(3-5 \mu \mathrm{m})$ and long wave $(8-12 \mu \mathrm{m})$ bands, and are more sensitive than early detectors (that operate in 1.9-2.9 $\mu \mathrm{m}$ band). They are capable of detecting IR radiation in a wider spectrum, and are also capable of locking-on to aircraft from all aspects, including from the front. Such systems are inherently immune to commonly used countermeasures like IR flares that appear as a point source [42]. New generation IR detectors are based on Quantum Well IR Photodetectors (QWIP) technology. They use multi-colour thermal-imaging systems that employ an array of detectors to build a spatial map of the scene [43-45]. Such detectors can eventually find a place in IR-guided missiles, making IR signature management even more stringent $[46,47]$

The safe flight envelope of an aircraft against IR detection depends upon the NEI of the detector; hence, it is an important operational constraint [40]. As illustrated in Fig. 3(a), the undetectable flight zone of aircraft can be predicted on the plot of altitude $H$ versus flight Mach number $M_{\infty}$. This demarcation on the flight envelope requires information on the IRSL of aircraft and NEI of the IR detector. This information is of particular importance for the design and operation of low observable aircraft. The IRSLs in the $8-12 \mu \mathrm{m}$ band [Ref. Fig. 3(a)] were obtained for an aircraft (with engine in dry mode) vertically above the detector on the ground. All the constant IRSL lines slope upwards because at higher $H$, the same IRSL is obtained at higher $M_{\infty}$; and the region above the IRSL $=$ NEI line is safe to fly [40]. Developments in IR-detection technology are pushing the NEI line upwards due to reduction in its value, thereby reducing the safe flight zone. But low IRSL engines push the NEI line downwards, as shown in Fig. 3(b) that illustrates IRSL of turbo-jet engine (TJE) and equivalent low bypass turbo-fan engine (TFE) with mixed exhausts producing the same thrust. The case without plume IRSL is applicable for the $8-12 \mu \mathrm{m}$ band, and gives the contributions from rear fuselage and airframe. The area enclosed between the two engines (for a given case) is the extra safe region obtained by changing from TJE to TFE. The engine casing's IRSL contribution is reduced in the TFE particularly at low $M_{\infty}$, and the exhaust plume's contribution is reduced at high $M_{\infty}$. a

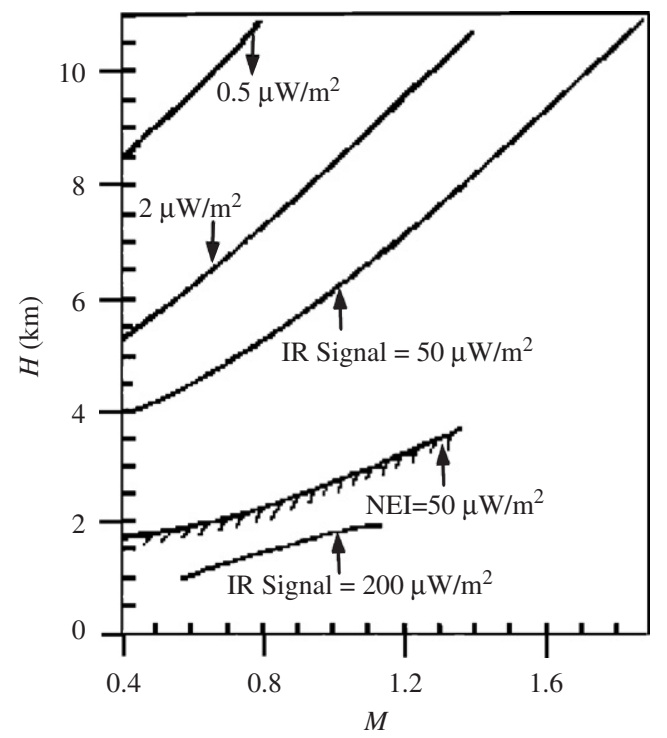

b

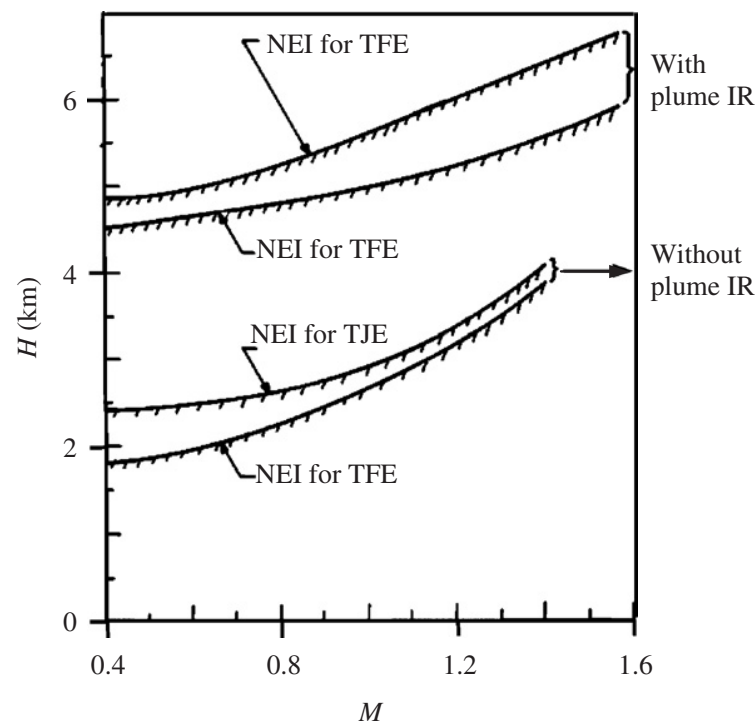

Fig. 3. Illustration of IRSLs on aircraft flight envelope (after [40]): (a) Loci of IRSLs on flight envelope for dry engine rating and (b) Loci of IRSL = NEI for TJE and TFE.

\subsection{Atmospheric transmission of IR and estimation of atmospheric IR-radiance}

The radiative characteristics of atmosphere are primarily governed by pressure, temperature, and concentration of $\mathrm{CO}_{2}, \mathrm{H}_{2} \mathrm{O}$ (vap.), and $\mathrm{O}_{3}$. The concentration of $\mathrm{H}_{2} \mathrm{O}$ (vap.) decreases rapidly with increasing $H$, and is absent above $10 \mathrm{~km}$; and the concentration of $\mathrm{O}_{3}$ is prominent only at an altitude of $20-30 \mathrm{~km}$. Other trace gases with asymmetric 
molecular structures, e.g. $\mathrm{CH}_{4}$ and oxides of nitrogen, affect atmospheric IR characteristics; but their contribution is small.

Radiant flux from the target is selectively absorbed by several atmospheric gases and scattered away by suspended particles in the atmosphere (e.g. aerosols). The transmissivity of the atmosphere determines the part of IR radiation emitted by the aircraft that reaches the IR detector and its intensity. There are a few bands in the IR spectrum where atmospheric transmission is high (known as atmospheric windows); within which, the IR detector must operate. The atmosphere also determines the background IR radiance (noise), thereby determining the contrast and IRSL of the target. The maximum detection range of the IR detector depends on its NEI and the contrast between target aircraft and atmospheric IR radiance [6]. The spectral distribution of atmospheric IR radiance is mainly due to the thermal emission by atmospheric gases and scattering of sunlight [48]. Scattering of radiation by the atmospheric particles is prominent only in the visible and near IR bands, and is observed during the daytime; hence, it is generally neglected [48]. Berger [49] developed a model for the evaluation of spectral emissivity and spectral IR radiance. It was proposed that spectral IR radiance is a function of ground level and dewpoint temperatures.

\subsubsection{Estimation of atmospheric transmission of $I R$ using LOWTRAN code}

The LOWTRAN code that calculates the atmospheric IR transmissivity and the background IRradiance was released in 1972 by the Air Force Geophysical Laboratory, USA. It is a comprehensive empirical-based program (based on band models of molecular absorption) with low spectral resolution of $20 \mathrm{~cm}^{-1}$, which can be used for $\lambda>0.2 \mu \mathrm{m}$ [50]. It considers spatial and temporal changes in atmospheric properties, and their effect on IR transmission. Fig. 4 shows the atmospheric transmissivity for the $1-20 \mu \mathrm{m}$ band obtained using the LOWTRAN code, for a vertical path length of $5 \mathrm{~km}$, for mid-latitude summer and tropical conditions. As seen from Fig. 4, there are several atmospheric windows, some of which are too narrow and insignificant; and $8-14 \mu \mathrm{m}$ is the widest. Also, atmospheric transmissivity beyond $14 \mu \mathrm{m}$ is negligible; hence, cannot be harnessed for aircraft detection [51]. The transmissivity is higher for the mid-latitude summer atmosphere than the tropical atmosphere, in the $8-14 \mu \mathrm{m}$ band [51].

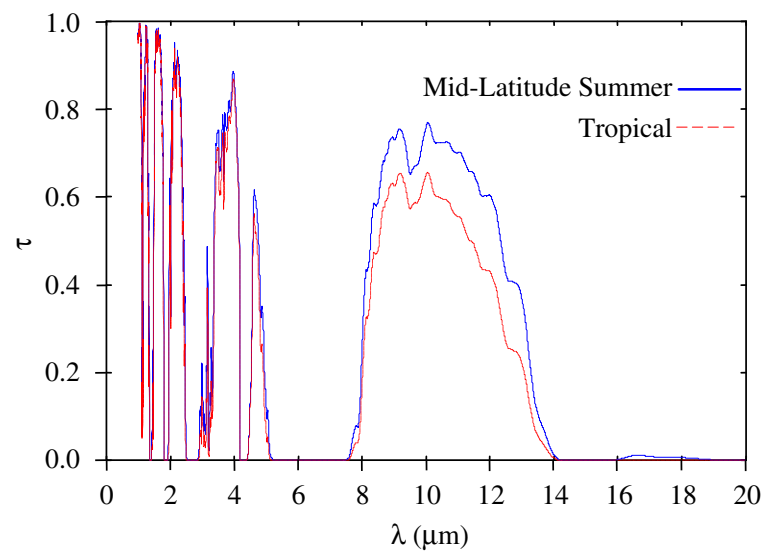

Fig. 4. Atmospheric transmission for mid-latitude summer and tropics (after [51]).

The LOWTRAN code and its higher variants are predominantly used in standard IR signature predictions codes like spectral infrared imaging of targets and scenes (SPIRITS), Infrared Seeker Trade-Off Requirements Model (IRSTORM), MIRSAT, etc. The LOWTRAN code and the higher-resolution MODTRAN code, take fixed number of discrete sea-level air temperatures. In the LOWTRAN code, the adiabatic lapse rate for each of the discrete model atmospheres is not explicitly defined [52]. Measurable error occurs whenever the assumed temperature deviates from the implicit model atmospheric temperature. This error is significant while modelling IR signatures from small, low flying, subsonic targets that are dominated by skin heating. Skin heating is determined by the speed of the target, sea-level air temperature, and the adiabatic lapse rate of the atmosphere [52]. The model having a sea-level air temperature with the smallest absolute error relative to the specified air temperature in model is used [52].

\subsubsection{Estimation of atmospheric IR-radiance using Berger's model}

Berger's model is an empirical method based on direct measurement of clear skies, using surface temperature and humidity. Atmospheric IR-radiance can also be derived from the detailed profiles of atmospheric constituents, together with knowledge of their radiative properties [53]. The model evaluates spectral emissivity $[49,54]$ and spectral radiance as a function of ground-level temperature and dew-point temperature (which is a function of humidity). The spectral sky emissivity in wavelength band $\Delta \lambda$ is obtained by an extension of Beer's 
Law as

$\varepsilon_{\Delta \lambda}=1-\exp \left(-k_{\Delta \lambda} w\right)$

where $k_{\Delta \lambda}$ is coefficient of absorption and $w$ is the equivalent absorber. The value of $k_{\Delta \lambda}$ cannot be considered as constant, due to $\mathrm{H}_{2} \mathrm{O}$ (vap.) absorption by the medium. The $\mathrm{H}_{2} \mathrm{O}$ (vap.) absorption spectrum consists of the following two parts: (i) the absorption owing to lines and (ii) the absorption due to overlapping of the wings outside of the absorption lines, which is regarded as a continuum [54]. The value of $w$ is proportional to the concentration of $\mathrm{H}_{2} \mathrm{O}$ (vap.) in the atmosphere [49]. Eq. (2) is strictly valid for monochromatic radiation, and is increasingly valid as the wavelength interval $(\Delta \lambda)$ approaches zero [55]. Values of $w$ and $k_{\Delta \lambda}$ are determined by the observed spectral sky emissivity, and by regression analysis. The $k_{\Delta \lambda}$ is given as

$k_{\Delta \lambda}=C_{1}+C_{2} t_{\mathrm{dew}}$,

where $C_{1}$ and $C_{2}$ for particular spectral interval $\Delta \lambda$ are given in Table 2 ( $\lambda$ is at the centre of $\Delta \lambda$ ). For day and night conditions, $w$ has two expressions for the entire 4-22 $\mu \mathrm{m}$ band (except in 9.3-9.6 $\mu \mathrm{m}$

Table 2

Values of coefficients $C_{1}, C_{2}$ in the linear expression of $k_{\Delta \lambda}$ (after [54])

\begin{tabular}{lrlr}
\hline$W_{1} / W_{2}$ & $\lambda$ & $C_{1}$ & \multicolumn{1}{l}{$C_{2}$} \\
\hline$W_{1}$ & 7.9375 & 1.000 & 0.0000 \\
& 8.6375 & 0.085 & 0.0028 \\
& 9.0000 & 0.102 & 0.0031 \\
& 9.2000 & 0.092 & 0.0027 \\
$W_{2}$ & 9.5000 & 0.124 & 0.0058 \\
& 9.8000 & 0.116 & 0.0058 \\
$W_{1}$ & 10.1500 & 0.104 & 0.0027 \\
& 10.8500 & 0.084 & 0.0044 \\
& 11.8000 & 0.134 & 0.0066 \\
& 12.1000 & 0.124 & 0.0071 \\
& 12.5000 & 0.252 & 0.0086 \\
& 12.9500 & 0.274 & 0.0082 \\
& 13.3750 & 1.137 & -0.0116 \\
& 13.8000 & 2.147 & -0.0391 \\
$W_{2}$ & 16.9250 & 1.455 & 0.0113 \\
& 18.0000 & 1.265 & 0.0299 \\
& 18.8000 & 1.431 & 0.0268 \\
& 19.5000 & 1.909 & 0.0208 \\
& 20.5000 & 1.885 & 0.0162 \\
& 21.1750 & 2.281 & -0.0065 \\
& 22.0000 & 2.671 & -0.0202 \\
\hline \multirow{3}{*}{} & & &
\end{tabular}

sub-band), which are given as [54]

$w_{1, \text { night }}=2.020 \exp \left(0.0243 t_{\mathrm{dew}}\right)$

and

$w_{1, \text { day }}=1.621 \exp \left(0.0193 t_{\text {dew }}\right)$.

When additional emission from $\mathrm{O}_{3}$ in $9.3-9.6 \mu \mathrm{m}$ band is considered, $w$ is given as

$w_{2, \text { night }}=4.050 \exp \left(-0.0212 t_{\text {dew }}\right)$

and

$w_{2, \text { day }}=3.317 \exp \left(-0.0182 t_{\text {dew }}\right)$.

Eqs (2.1)-(2.5) are valid for the 4-22 $\mu \mathrm{m}$ band, in which, $\mathrm{H}_{2} \mathrm{O}$ (vap.) is radiatively participating. The value of $t_{\mathrm{dew}}$ can be obtained from the psychrometric chart if any two properties of air, viz. dry bulb or wet bulb temperature, and relative or absolute humidity, are known. This model can be used to determine the total emissivity (by integrating spectral emissivity) and directional spectral emissivity of clear sky at different altitudes.

The spectral radiance of the sky obtained by Berger's model, as received by an IR-detector on the ground for mid-latitude summer $\left(t_{\mathrm{g}}=21^{\circ} \mathrm{C}\right.$ and $t_{\text {dew }}=16^{\circ} \mathrm{C}$ ) conditions, is shown in Fig. 5(a). As the view angle approaches the horizon $\left(0^{\circ}\right)$ from the zenith $\left(90^{\circ}\right)$, the spectral radiance of the atmosphere approaches that of a black body at ground-level temperature [56]. This is attributed to the significantly increased path-length through the atmosphere for horizontal beam, and increased attenuation of IR-radiation at lower altitude. The path-length of a horizontal beam through the atmosphere is, $\left[H_{\mathrm{atm}}\left(H_{\mathrm{atm}}+2 R_{\mathrm{e}}\right)\right]^{0.5}$, and the pathlength of a vertical beam is $H_{\text {atm }}$ [Ref. Fig. 5(b)]. Therefore, the maximum ratio of horizontal-tovertical path-lengths is given as, $\left[1+2\left(R_{\mathrm{e}} / H_{\mathrm{atm}}\right)\right]^{0.5}$. The ratio of slant-to-horizontal path-lengths reduces to unity from this maximum value, as the slant angle changes from $90^{\circ}$ to $0^{\circ}$. Further, at lower $H$, the concentration of $\mathrm{H}_{2} \mathrm{O}$ (vap.) and $\mathrm{CO}_{2}$ is much higher; which also increases the absorption of IR-radiation in horizontal beam. At ground level, the atmospheric radiance is dominated by $\mathrm{H}_{2} \mathrm{O}$ (vap.), whose concentration may vary from $0.2 \%$ to $4.0 \%$ by volume, depending on temperature and humidity [55]. At $6.3 \mu \mathrm{m}$ [centre of $\mathrm{H}_{2} \mathrm{O}$ (vap.) emission band] and $15 \mu \mathrm{m}$ [centre of $\mathrm{CO}_{2}$ emission band], the spectral emissivity of the sky is high; and the peak around $9.6 \mu \mathrm{m}$ is due to $\mathrm{O}_{3}$-emission. Radiance by $\mathrm{CO}_{2}$ is prominent around $4.3 \mu \mathrm{m}$ 
a

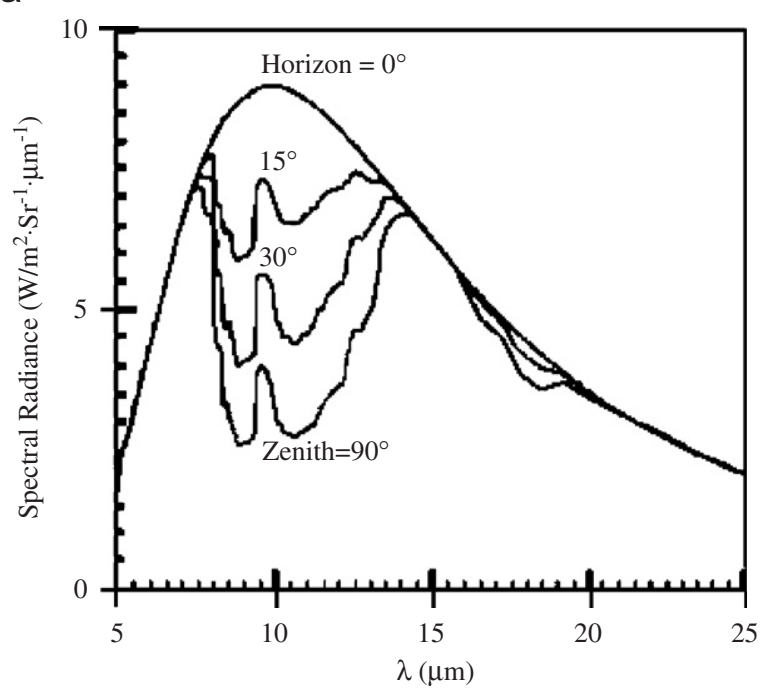

b

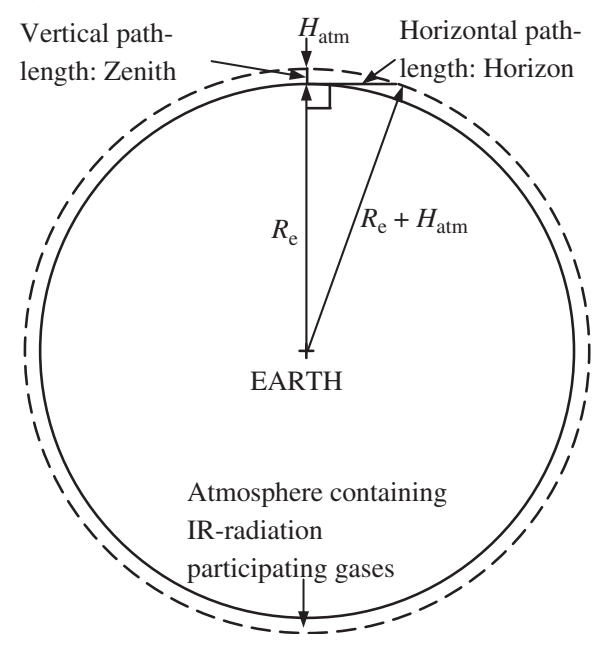

Fig. 5. Spectral sky radiance from zenith to horizon: (a) spectral radiance of sky for mid-latitude summer atmosphere (after [51]) and (b) Illustration of path-lengths of horizontal and vertical beams.

because of its vibrational band; but at this wavelength, the spectral emissive power of the atmosphere is negligible [51]. Berger's model predicts atmospheric IR-radiance accurately, except in $16-20 \mu \mathrm{m}$ band (which is not of significance for IR signature studies). Fig. 6 shows the contrast between aircraft and background (predicted using Berger's model) IR radiance in dry mode, for tropical and mid-latitude summer atmospheric conditions. The negative radiance in some bands is because atmospheric IR radiance (estimated from Berger's model) exceeds the aircraft IR radiance. The positive contrast is higher for mid-latitude summer than

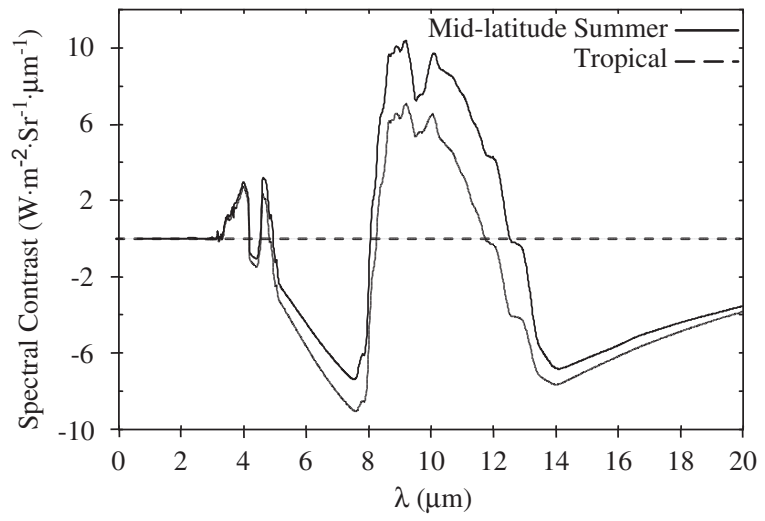

Fig. 6. Spectral contrast between aircraft and background IR radiance (after [51]).

tropical atmosphere but negative contrast is higher for the later, because the background IR-radiance is higher for the later. The highest contrast is in $8-12 \mu \mathrm{m}$ band due to rear fuselage skin contribution.

The conjugate role of atmospheric transmission of IR radiation and background IR radiance (using Berger's model), on aircraft susceptibility against SAM, was examined [51]. It was found that: (i) when the engine tailpipe is not visible, aircraft IRSL is prominent in the $3.24-4.18,4.50-4.93$, and $8.20-11.80 \mu \mathrm{m}$ bands; (ii) when the engine tailpipe is visible, aircraft IRSL is also significant in the $1.95-2.50$ and $2.92-3.20 \mu \mathrm{m}$ bands; (iii) atmospheric IR radiance is dominant only in $8-12 \mu \mathrm{m}$ band and is insignificant in lower wavelength bands; and (iv) the aircraft rear fuselage is a prominent source of IRSL in the $8-12 \mu \mathrm{m}$ band. Therefore, an aircraft is susceptible from the front to all-aspect IR-missiles in the $8-12 \mu \mathrm{m}$ band.

\subsection{Role of earthshine in IRSL}

Earthshine is the IR radiance from the earth's surface (determined by ground temperature and emissivity) that is reflected from the aircraft surface and then collected by IR-detector. Its estimation is important in the $8-12 \mu \mathrm{m}$ band for aircraft flying at low altitude (typical of a bombing mission), and its effect is insignificant in the $3-5 \mu \mathrm{m}$ band [57]. As shown in Fig. 7, the variation of IR contrast with emissivity in the $3-5 \mu \mathrm{m}$ band is almost the same with and without the effect earthshine [57]. In both bands, the slope is higher without earthshine; because the earthshine contribution to IR contrast increases with decreasing emissivity. This dependence of the earthshine contribution is the opposite 


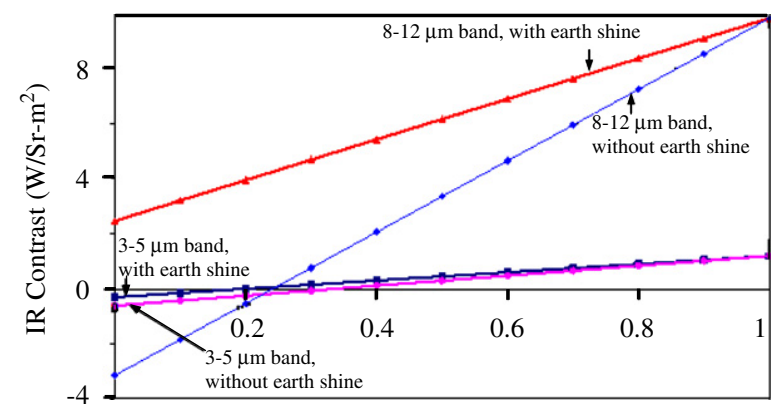

Fig. 7. Effect of earthshine on IR contrast in $3-5$ and $8-12 \mu \mathrm{m}$ bands (after [57]).

of temperature-based emission, which increases with emissivity. The emission from the earth is a function of several parameters, e.g. soil type, water body (lakes, ocean), vegetation, temperature of soil, humidity, etc. [58]. Because models for estimating the emissivity of surfaces of the earth are not reported, measured values have to be used for earthshine calculations [58]. Most surfaces of the earth behave as diffuse grey bodies with high emissivity, and Eq. (1) can be used for estimating emission from earth's surfaces. Most agricultural plants have emissivity close to 0.93 ; therefore, agricultural soil behaves as diffuse radiator with emissivity close to 0.93 [59].

\section{Analysis and modeling of IR signatures}

The main sources of IRSL in aircraft are: powerplant, nozzle, exhaust plume, and airframe [40]. Among these, the powerplant is the major source of IR emission because of the large amount of heat produced by the gas turbine engine. Plume radiation is visible from all aspects, because of its dimensions and orientation [60]. The aircraft surfaces radiate predominantly in the $8-14 \mu \mathrm{m}$ band, whereas the engine exhaust jet radiates strongly in the $2-6 \mu \mathrm{m}$ band [61]. The IRSL of aircraft can be obtained by analytical model (physics/empirically based) or by experimental measurements. There are two methods for experimental measurements: static engine testing and wind tunnel testing. In the former method, the engine is instrumented and set up in an outdoor test facility, while the later method employs a scaled aircraft model in a wind tunnel [62].

For a re-entry vehicle, the sources of IR emission are as follows: (i) shock heated air in front of body, (ii) heated body surface, (iii) ablation products in the vicinity of the body, and (iv) the wake behind the body [37]. Prediction of IR emissions from a reentry vehicle involves the following [37]: (i) determination of the whole trajectory and finding variations of altitude, speed, density, and angle of incidence along the trajectory; (ii) determination of shock structure, and boundary layer along the body; and (iii) determination of surface temperatures using combined convection, conduction, and radiation heat transfer model.

\subsection{Analysis of powerplant and rear fuselage IR signature}

The aircraft rear fuselage has a large surface area at relatively low temperature, which is primarily heated by the embedded powerplant and external aerodynamic heating by the freestream. Earthshine and skyshine reflections add to IR emissions from the rear fuselage, and become especially important in $8-12 \mu \mathrm{m}$ band for low surface emissivities. The engine casing and nozzle act as grey bodies and emit radiation in all IR bands, thereby making IRdetection easier. Afterburner flames further enhance IR emissions from the powerplant [63], due to the much higher temperatures of chemically reacting species and the glowing carbon particles.

Mahulikar [64] and Mahulikar et al. [65] developed a multimode thermal model for predicting the rear fuselage skin temperature. Variations in transport and flow properties with temperature, and effect of cross-sectional area variation, heat transfer and skin friction, were also considered [65]. Fig. 8 shows the rear fuselage skin, jet pipe, and radiation shield temperature variations along the jet pipe length, in dry and afterburning modes. The temperature variations in the afterburning mode have been generated in this investigation using the modified thermal model reported in [65]. Afterburning significantly increases the rear fuselage skin temperature, as is evident upon comparing temperatures in dry mode [Fig. 8(a)] and afterburning mode [Fig. 8(b)]. In the afterburning mode, the temperature of the jet pipe almost doubles, while the rear fuselage skin temperature increases by about $70 \mathrm{~K}$. Apart from hot combustion products in the powerplant, aerodynamic heating also has a significant effect on the rear fuselage skin temperature. The freestream flow external to the rear fuselage skin acts as a heat sink at low $M_{\infty}$, when aerodynamic heating is lower than the heat received from the jet-pipe. But at high $M_{\infty}$, the freestream 
a

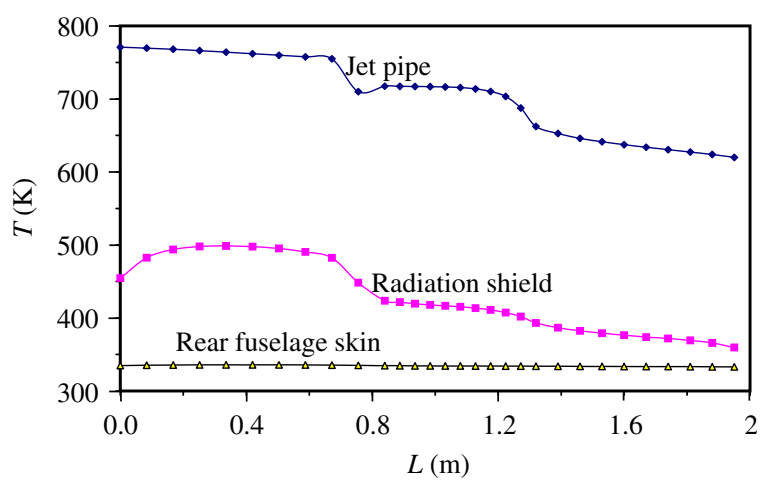

b

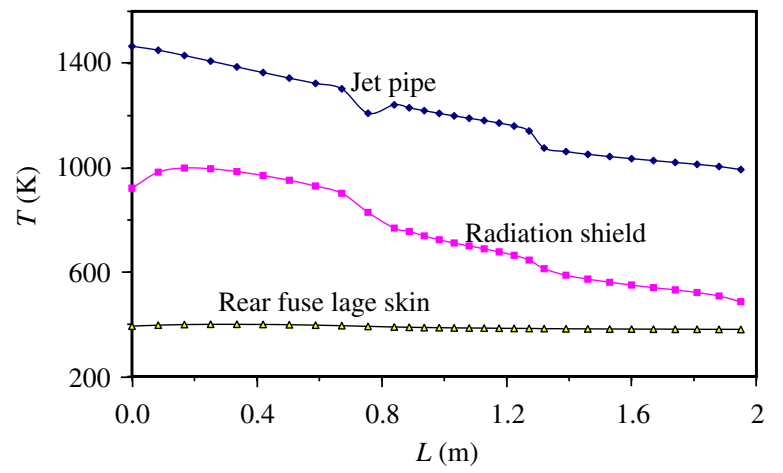

Fig. 8. Axial temperature distribution along jet pipe length: (a) dry mode (after [65]) and (b) afterburning mode.

flow acts as a heat source, due to higher recovery temperature [65]. This change occurs at certain combinations of $M_{\infty}$ and $H$, respectively termed as, transition $M_{\infty}\left(M_{\infty}\right.$,trans $)$ and transition $H$ ( $\left.H_{\text {trans }}\right)$

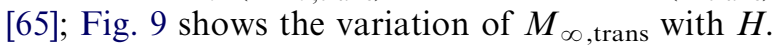
When the freestream acts as heat source for $M_{\infty}$ $>M_{\infty \text {,trans, }}$, the IRSL from the rear fuselage skin is lower than the IRSL from the rest of the airframe. For $M_{\infty}<M_{\infty}$,trans, the IRSL from rear fuselage skin is greater than that from the rest of the airframe [65]. These changes in the role of heat sink/ source of the embedded engine and freestream flow, for different $H$ and $M_{\infty}$, are summarized in Table 3. These relative differences in IRSLs of aircraft surfaces can be effectively used for generating wire map/approximate dimensions of low flying aircraft by imaging IR detectors.

For different viewing aspects $(\phi)$, the solid angle $(\Omega)$ subtended by the surfaces of the engine hot parts change, which alters the IRSL as perceived by the IR-guided missile. Especially during the terminal phase, the $\Omega$-subtended by the hot surfaces increase and the engine hot parts appear as well-resolved

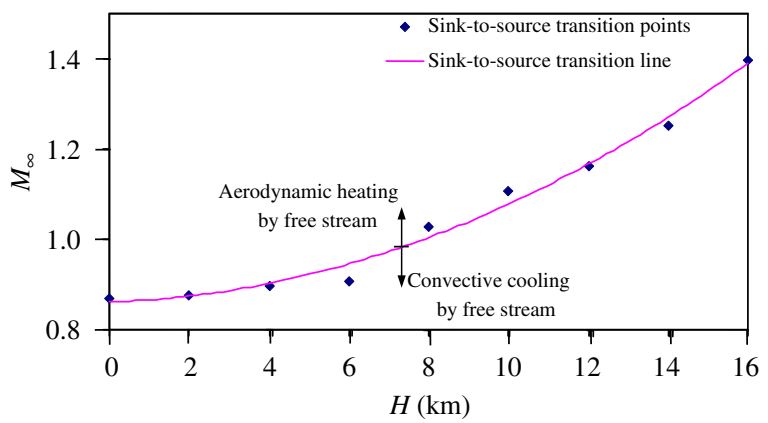

Fig. 9. Effect of $H$ and $M_{\infty}$ on role of freestream in rear fuselage skin IRSL (after [65]).

Table 3

Role of $H$ and $M_{\infty}$ on IRSL of rear fuselage skin

\begin{tabular}{llll}
\hline & $\begin{array}{l}\text { Role of } \\
\text { engine }\end{array}$ & $\begin{array}{l}\text { Role of } \\
\text { freestream }\end{array}$ & IR-signature \\
\hline $\begin{array}{l}H<H_{\text {trans }} ; \\
M_{\infty}>M_{\infty} \text {,trans }\end{array}$ & Cooling & Heating & $\begin{array}{l}\text { Lower than } \\
\text { airframe }\end{array}$ \\
$\begin{array}{l}H>H_{\text {trans }} ; \\
M_{\infty}<M_{\infty} \text {,trans }\end{array}$ & Heating & Cooling & $\begin{array}{l}\text { Higher than } \\
\text { airframe }\end{array}$ \\
\hline
\end{tabular}

sources of complex geometry. Therefore, $\Omega$-subtended by each component of the engine and rear fuselage skin must be estimated separately, to assess the IR-irradiance incident on the missile's detector. Mahulikar et al. [66] analytically estimated the $\Omega$-subtended by typical fighter aircraft engine layout for different $\phi$, using Parallel Rays Projection method. The engine layout comprises of visible surfaces of turbine exit disc, jet-pipe, and C-D nozzle, as engine hot parts; and rear fuselage outer surface. The layout is considered as a well-resolved distributed source of IR-radiation due to increase in angular subtense as it approaches the IR-detector. Because the axial temperature variation of jet-pipe and $\mathrm{C}-\mathrm{D}$ nozzle inner surfaces is high [65], it is necessary to consider their axial variation of $\Omega$-subtended. Fig. 10 shows the distribution of $(\Omega / l)$ with $\phi$ for typical jet-pipe and $\mathrm{C}-\mathrm{D}$ nozzle inner surfaces; where, $\phi=0^{\circ}$ is the aspect perpendicular to axis, and $\phi=90^{\circ}$ is along the axis. The $\Omega$-subtended by the convergent-section and jet-pipe are much smaller than that subtended by the divergent-section. The jet-pipe and convergent nozzle are visible only in a narrow range of $\phi$ as the throat section blocks their view; but the visibility of the divergent-section is over the complete range of $\phi\left(0^{\circ}-90^{\circ}\right)$. Therefore, considering low IRSL requirement from the rear 
aspect, use of divergent-section is not a prudent design, though engine performance can be augmented.

\subsection{Analysis of plume IR signature}

The aircraft plume mainly consists of gases like $\mathrm{H}_{2} \mathrm{O}$ (vap.), $\mathrm{CO}_{2}, \mathrm{CO}$, and their solid and liquid phases [67]. Amongst these, $\mathrm{CO}_{2}$ is the most important IR-radiation participating species [68]; and other gaseous constituents like $\mathrm{O}_{2}, \mathrm{~N}_{2}$, and $\mathrm{NO}_{X}$ are insignificant emitters of IR [69]. The IR radiation from the plume is emitted by the vibrational energy of the gaseous species, and thermal energy of solid and liquid species. The plume length is several times more than the aircraft length; therefore, plume radiation is visible from a much

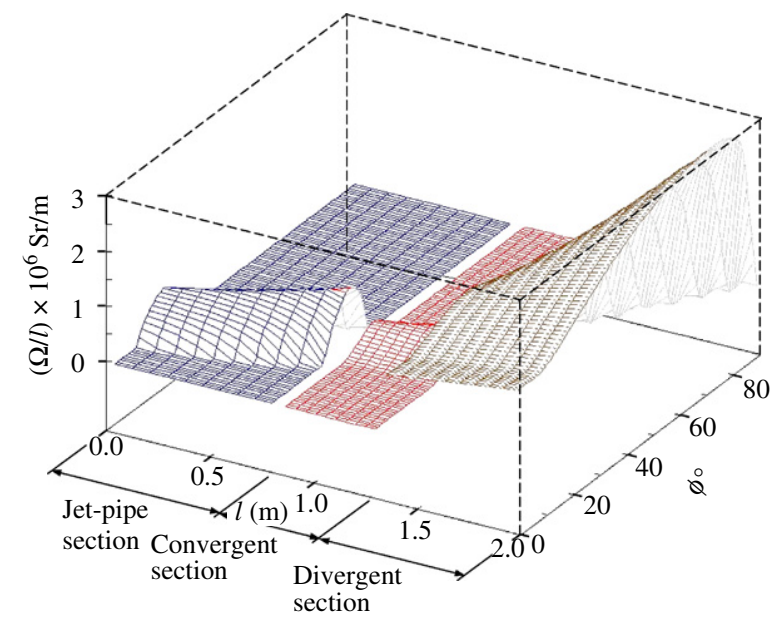

Fig. 10. Distribution of $(\Omega / l)$ for jet-pipe and C-D nozzle inner surfaces (after [66]). wider view angle. Length, diameter, and temperature profiles of the plume for a TJE and a TFE are shown in Fig. 11. The plume size of the TJE is bigger relative to that of the TFE, resulting in higher IR emissions from the plume of the TJE as compared to the TFE. The emissivity of a gas volume is a function of temperature, pressure, molar concentration of gases, and the optical path length. The temperature distribution of a plume from a circular nozzle exit is axisymmetric, which simplifies prediction of the plume structure. The IR intensity along the centreline of an axisymmetric plume remains constant in the potential core region, because the static temperature and $\mathrm{CO}_{2}$ concentration do not vary [68].

A simple descriptive model for plume IR radiation estimation is given by Decher [67] and Chu et al. [70]. A mixed turbofan is analysed for the effect of length of core, spectral optical depth, and nozzle size of high aspect ratio nozzles, on IR signature characteristics [67]. Increasing the aspect ratio reduces the IR emission, e.g. an aspect ratio of 8 is required to reduce the IR radiation by a factor of 2 [67]. A simple modelling technique for predicting the detailed flowfield from a 2-D convergent-divergent nozzle plume is presented, and compared with experimental results [70]. The predicted total temperature contours obtained from modelling are in good agreement with the experimental total temperature contours. The width of the plume predicted by this model is quite accurate when compared with the experimental results [70]. Heragu et al. [61] and Heragu and Rao [71] gave a comprehensive scheme for the prediction of

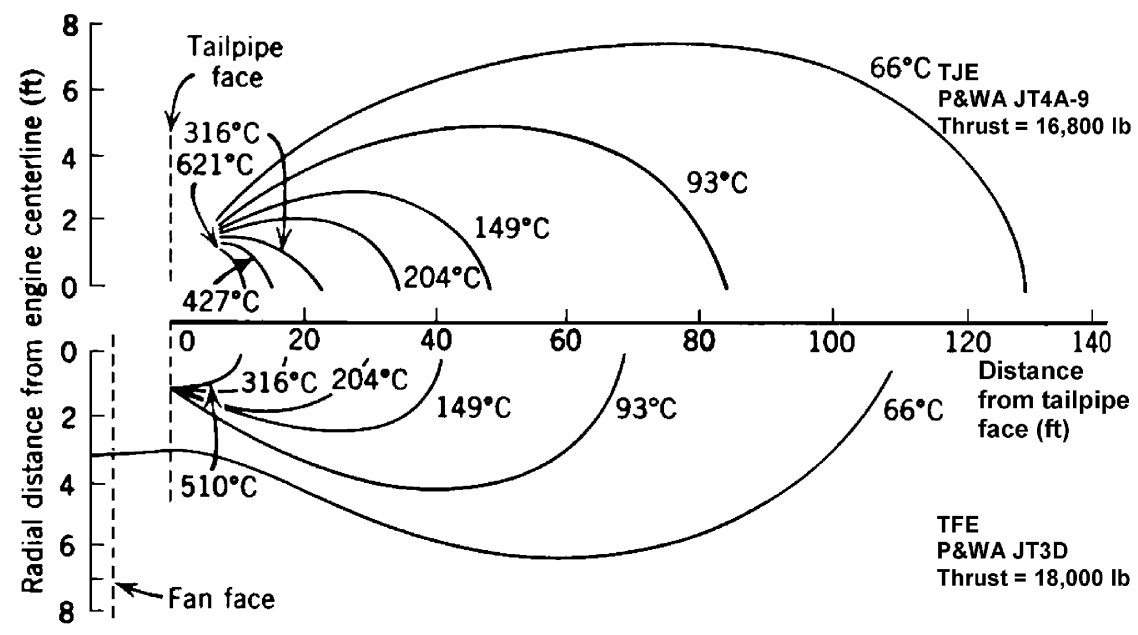

Fig. 11. Exhaust temperature contours of TJE and TFE (after [6]). 
radiation from an engine exhaust plume, based on the combination of radiation from the surface and the gaseous plume. The modelling determines the complicated geometry of the radiating volume consisting of jet and nozzle surfaces. The model predicts important peaks (which are experimentally validated) at 2.7 and $4.3 \mu \mathrm{m}$, corresponding to emission from $\mathrm{CO}_{2}$. A peak at $5.8 \mu \mathrm{m}$ is also predicted that corresponds to nozzle surface radiation at its temperature [61]. The Standardized Infrared Radiation Model (SIRRM) code developed under JANNAF (Joint Army Navy NASA Air Force) project, predicts IR radiation from missile and aircraft plumes [72]. The code also predicts the effect of carbon particles on IR emission characteristics of plume. Bakker et al. [73] gave a brief methodology for computing plume IR signatures from naval ship gas turbine engines, using NATO's NPLUME program for exhaust field computations.

Hypothetical band models for plume IR-radiation modelling are classified into narrow-band and wide-band models. Wide-band models are used for obtaining total quantities, while narrow-band models are used for spectral information [61]. Ibgui and Hartmann [74] and Ibgui et al. [75] developed an optimized line-by-line FORTRAN code for the calculation of aircraft plume IR signature. The results obtained by the model were in good agreement with the measured laboratory simulation results. Soufiani and Taine [76] obtained the emis.sivity of gases resulting from hydrocarbon combustion by using a statistical narrow-band model, which provides fast results at reasonable accuracy [77]. The effect of Line Doppler Shift (LDS) is important when there is a relative velocity between radiating gas layers, e.g. aircraft plume [77]. Consideration of LDS-effect on plume IR predictions using narrow-band model shows apparent increase in radiance compared to calculations by line-by-line techniques [77].

Computational Fluid Dynamics (CFD) simulation of aircraft plumes for obtaining temperature, pressure, and concentration distributions is also reported [78]. It is inferred that the spectral intensity of aircraft plumes as received by IR-guided SAMs in non-afterburning mode, is prominent only in the 4.14-4.45 $\mu \mathrm{m}$ band (Fig. 12) [79]. In non-afterburning mode, the IRSL from the plume is much lower than from the tail-pipe and rear fuselage, which is contrary to popular belief. Further, there is no emission from gaseous plumes in the $8-12 \mu \mathrm{m}$

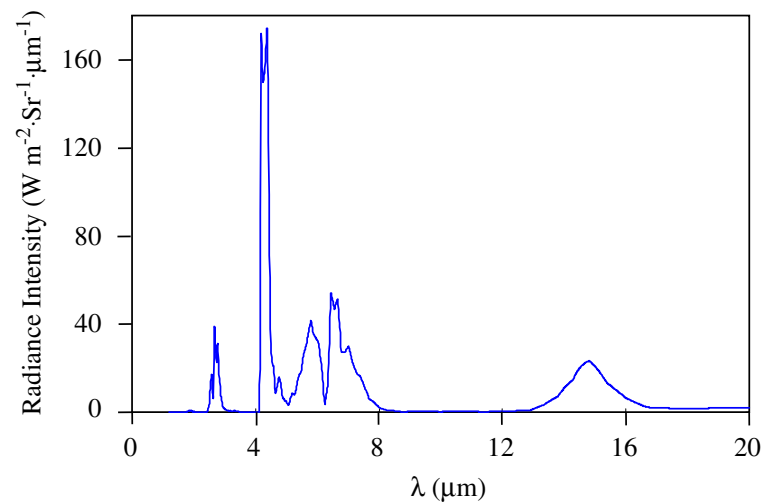

Fig. 12. Spectral radiance intensity of aircraft plume (after [79]).

band (even in afterburning mode); but solid surfaces being grey, emit at all wavelengths at all temperatures. Plume IR signatures were measured experimentally by Cogliandro and Castelli [80], using Rolls-Royce GEM.2-MK.1000 engine delivering $750 \mathrm{hp}$. Comparison of experimental results with theoretical results showed that the experimental results in $1-14.5 \mu \mathrm{m}$ band are accurate within $10 \%$.

The IR emission from rocket plumes is of interest for its role in base heating and engine performance diagnostics. It is also of importance in strategic functions like early warning, surveillance, acquisition, and tracking [81,82]. Parameters affecting plume IR signature can be grouped into four categories, viz. engine, vehicle, flight, and ambient. The engine parameters are mass flow rate, propellant type, mixture ratio (ratio of oxidizer mass to fuel mass), chamber pressure, area ratio, and nozzle contour. Vehicle parameters include number of nozzles, nozzle spacing, cant angle, and base diameter. Altitude, velocity, and angle of attack are flight parameters; and solar azimuth/elevation and earthshine/sunshine/skyshine are ambient parameters [81]. A rocket plume radiates strongly near $4.3 \mu \mathrm{m}$, because of the $\mathrm{CO}_{2}$ band; but burning of combustible species is most striking in missiles flying below $30 \mathrm{~km}$ [83]. Due to this continuing combustion reaction after the nozzle exit, the plume temperature and IR signature are raised [84-86]. The IR emission from rocket plume is sensitive to concentration of carbon particles in the plume. For the same concentration of carbon particles, variation in their size has no effect on IR emissions from the plume [84]. High altitude plume radiates more IR signature than at sea level; because for same nozzle exit conditions, high altitude plumes are bigger than the plume at sea level [87]. 
Avital et al. [88] developed computer code INFRAD for prediction of rocket plume radiative characteristics. The code results were compared with the experimental measurements on under-expanded exhaust plume generated by solid-propellant Ballistic Evaluation Motor (BEM). The code accurately describes the basic gas dynamics of the plume, and its thermodynamic and radiative properties. It predicts the spatial structure of the plume and its spectral radiative intensity within $10 \%$ accuracy as compared to experimental measurements.

\subsection{Standard models for prediction of IR signature}

All major military research establishments have developed their own models for prediction of IRSL from aircraft. These models can be grouped into three categories: (i) models for prediction of IR emissions from plume, powerplant, and complete aircraft, e.g. SIRUS, SIRRM, NATO Infra-Red Air Target Model (NIRATAM), SPIRITS, IRSTORM, MIRSAT, OPTASM, etc. [52]; (ii) Models for obtaining atmospheric IR transmissivity and radiance like LOWTRAN, MODTRAN, and HITRAN; (iii) Models for IRSL processing and generating spatial scene map, wire model generation like SPIRITS, infrared search and track (IRST), imaging infrared (IIR), electro-optical signature evaluation system (EOSAS), etc. Models for IRSL prediction of ships like SHIPIR and for ground vehicles like GTSIG and Physically Reasonable Infrared Signature Model (PRISM) are also used [89-91]. These standard analysis models can progressively be made more perfect by experimental validation, so that they can be used in digital IR simulators.

\subsubsection{NIRATAM}

The NIRATAM code is the result of NATO's eight-member nation's research group, which was first released in 1991. It is based on field measurements, theoretical studies, and IR data analysis performed over several years. It predicts the IRSL of aircraft in its natural environment, and a version of NIRATAM predicts IR emissions from re-entry vehicles [37,92]. The model considers IR radiation emitted by internally and aerodynamically heated surfaces, hot engine parts, combustion gases, and plume particles. It also considers the effect of sky radiation, sunshine, earthshine, atmospheric transmission, and emission between target and observer [37].

\subsubsection{SIRUS}

The Advanced Technology Centre (ATC) of British Aerospace Systems has developed this code for the IR predictions from air breathing and rocket motor propelled vehicles. The properties modeled by the code include the following: (i) surface temperature, (ii) surface reflectance, (iii) cavity physics, (iv) plume gas radiative transfer, (v) atmospheric effects (including solar contribution), and (vi) background and imaging sensor effects (imaging and threshold detection) [93]. The SIRUS code, which is based on the parameterized Bi-Directional Reflectance Function (BDRF), also has the capability to assess IR characteristics of paints used on airframes.

\subsubsection{IRST}

Aerodyne Research Inc. (USA) has developed the IRST model in 1989, to simulate long-range air-toair detection and tracking engagements. The code was created by integrating the following eight standalone modules [94]: (i) SPIRITS (aircraft IR signatures imaging module), (ii) CLOUD (sky background imaging module), (iii) LOWTRAN, (iv) TRACKER (signal processing and tracking module), (v) IPAS (optical sensor and spatial processing module), (vi) MISSION (dynamic trajectory module), (vii) ENGAGER (integrates all modules), and (viii) HIGH-LEVEL SCENARIO SPECIFIER (user-interface module).

Signature Technology Laboratory at GeorgiaTech. Research Institute, USA, developed the Imaging Infrared (IIR) missile model. This model evaluates advanced detection, tracking, and signal processing, against weakly contrasted targets [95]. The IR image synthesis model for a moving object was developed by $\mathrm{Yu}$ and Liu [96], while $\mathrm{Yu}$ et al. [97] developed a model for high-speed targets. Sundberg et al. [98] developed the Quick Image Display (QUID) model for rapid real-time target IR imagery, and for the estimation of spectral IR signatures. These reported trends in the progress in imaging seekers and microprocessors processing speed are significantly increasing the lethality of anti-aircraft missiles [47,99].

\subsection{Adequacy of analysis methods vis-à-vis experimental measurements}

The confidence in understanding of IR signatures of aerospace vehicles can be improved by experimental measurements and their analyses. There are 
two categories of IR prediction models: (i) empirically based, and (ii) physics based. In the former, IR measurements are obtained on operating aircraft at multiple aspects and operating conditions, and the data is analyzed to fill the gaps in prediction [13]. In the later, aircraft geometry, surface emissivity, temperature profile, and surface reflections, are inputs to the model [13]. Experimental measurements of IRSL require an aircraft to be flown over predetermined path and operating conditions, determined by $H$ and $M_{\infty}$. The majority of research in IR signatures of aerospace vehicles is undertaken by military research establishments, relative to academia. Therefore, there is a scarcity of details in the open literature in both analysis and measurement techniques. Investigations using experimental measurements were very few and mostly made for plume IR signature measurements. About 10-12 standard IRSL prediction models, based on a blend of analysis and experimental measurement techniques were developed worldwide. However, the underlying physics of these models and their prediction efficiency is kept under wrap. Due to difficulties in arranging experimental measurements, standalone analyses methods are preferred; as they involve less infrastructure, external dependencies, and cost. Analytical prediction methods are much less expensive, but less accurate compared to experimental measurements due to uncertainties in input parameters. Validation with experimental measurements and subsequent improvement makes analytical models more accurate. Such models are immensely useful in digital simulators and for the design of aircraft stealthy with respect to IRSL. Experimental validation of analytical work has been undertaken by standard IRSL prediction model developers; e.g. NIRATAM, SIRUS, etc. The NIRATAM is validated and developed using field measurements on Tornado, European F-16, F-4, Mirage, and F-104 [92].

The major shortcomings of the analysis methods can be summarized as follows:

(a) Analysis methods/models are inherently inaccurate due to uncertainties in input parameters, unless they are validated by experimental measurements.

(b) Because analysis methods are developed in modules, there can be errors resulting from coupling between modules. As an illustration, the aircraft rear fuselage is also heated by the plume, in addition to internal heating by an embedded gas turbine engine and external by aerodynamic heating. Therefore, consideration of exhaust plume orientation is also important for IRSL prediction from the rear fuselage skin.

(c) Prediction of IRSL from the engine also involves several miscellaneous parameters, e.g. engine throttle setting, cooling system, and hot gas streaks [13].

(d) Multiplicity of aircraft, diversity in aircraft mission planning, and availability of several IR-guided missiles, has increased the uncertainties in IRSL prediction models.

\subsection{Lock-on versus lethal envelope and target susceptibility}

The lock-on envelope is defined as the locus of points around a target where the missile's IR seeker locks-on to the target; it has been used to evaluate target susceptibility. Due to advances in IR detectors, missiles are generally constrained by their burn-out range; therefore, the lock-on envelope is inadequate for target susceptibility assessment. The lock-on envelope does not incorporate several other important parameters [100]; e.g. target aircraft $\left(V_{\mathrm{ac}}\right)$ and missile $\left(V_{\mathrm{m}}\right)$ velocities, missile burn-out range, etc. The lethal envelope [100] is the locus of points around the target aircraft, within which, if the missile is launched, there is a high probability of the missile hitting the target. The lethal envelope is a function of target aircraft lock-on envelope, target aircraft velocity, missile burn-out range, missile blast-kill radius, etc. Fig. 13(a) shows the 2-D lockon and lethal envelope plots for military aircraft; for which, it is assumed that the target aircraft is an isotropic point source of IR radiation. Therefore, the lock-on range $\left(R_{\mathrm{LO}}\right)$ is constant in all aspects; i.e. the lock-on envelope is a perfect circle. The attacking and target aircraft are assumed to be in the same horizontal plane, and the target aircraft is assumed not to be taking any countermeasures against the approaching AAM. The variation of $A_{\text {lethal }}$ (area of lethal envelope) with $R_{\mathrm{LO}}$ for different $\left(V_{\mathrm{ac}} / V_{\mathrm{m}}\right)$ is in Fig. 13(b). The curves with higher $\left(V_{\mathrm{ac}} / V_{\mathrm{m}}\right)$ have smaller $A_{\text {lethal }}$, due to decrease in tracking rate by the missile; i.e. an increase in $V_{\text {ac }}$ reduces $A_{\text {lethal }}$, making the target aircraft less susceptible.

It is of significance to find the threshold amount by which the target's IRSL should be reduced, to achieve the desired reduction in its susceptibility. This enables gauging of the effectiveness of IRSS 
a

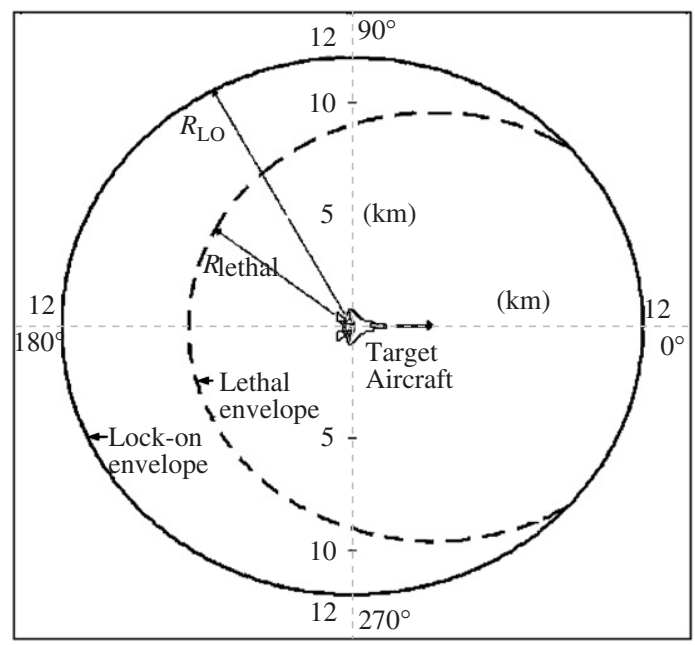

b

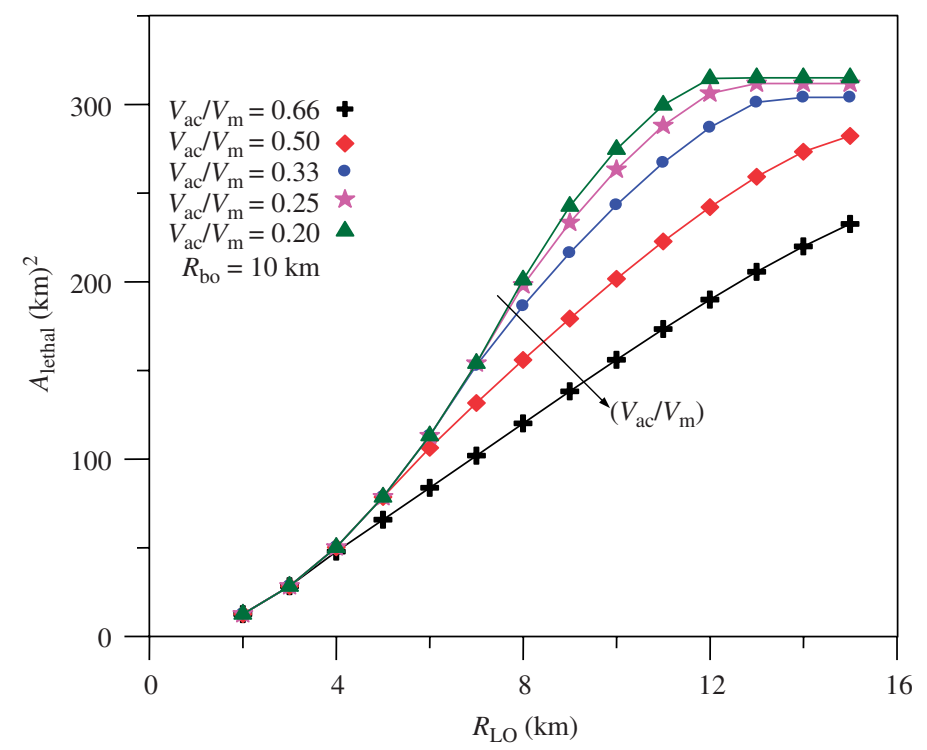

C

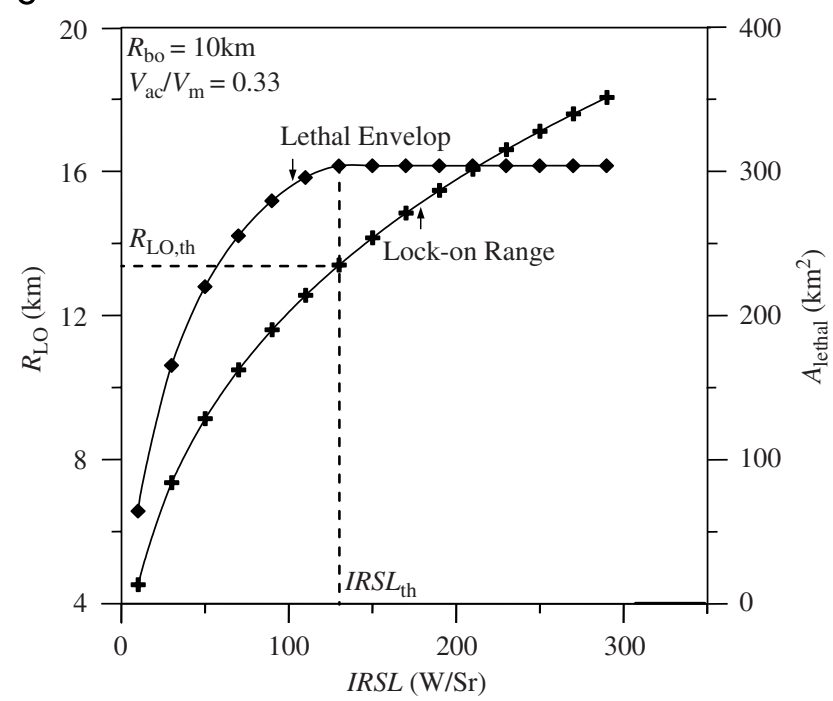

Fig. 13. Illustrations of lethal and lock-on envelops, and IRSL for a military aircraft (after [100]): (a) lock-on and lethal envelopes of target aircraft as isotropic source of IR radiation $\left(R_{\mathrm{LO}}=12 \mathrm{~km}, R_{\mathrm{bo}}=10 \mathrm{~km}\right)$; (b) variation of lethal envelope with lock-on range for different velocity ratios and (c) variation of lethal envelope and lock-on range with aircraft IRSL.

systems for different operating conditions. A model was developed to find the relation between IRSL and target susceptibility, and the threshold IRSL $_{\text {th }}$ [100]. The lock-on envelope increases monotonically with target IRSL; but the lethal envelope initially increases with target IRSL, and then attains a constant value at IRSL $_{\text {th }}$ [Ref. Fig. 13(c)]. Therefore, the IRSS system is effective only if it can reduce the target IRSL below the $\mathrm{IRSL}_{\mathrm{th}}$, else it only results in performance penalties.

\section{IR countermeasures (IRCMs)}

The development of IRCM technology got an impetus ever since the lethality of IR-guided missiles was first realized in the Vietnam War. The IRCMs can be classified in two categories, Passive (termed as IR suppression) and Active (e.g. decoys); illustrated in Fig. 14. Compared to fixed wing aircraft, helicopters operate at lower altitudes and speeds, and have limited manoeuvrability; hence, 


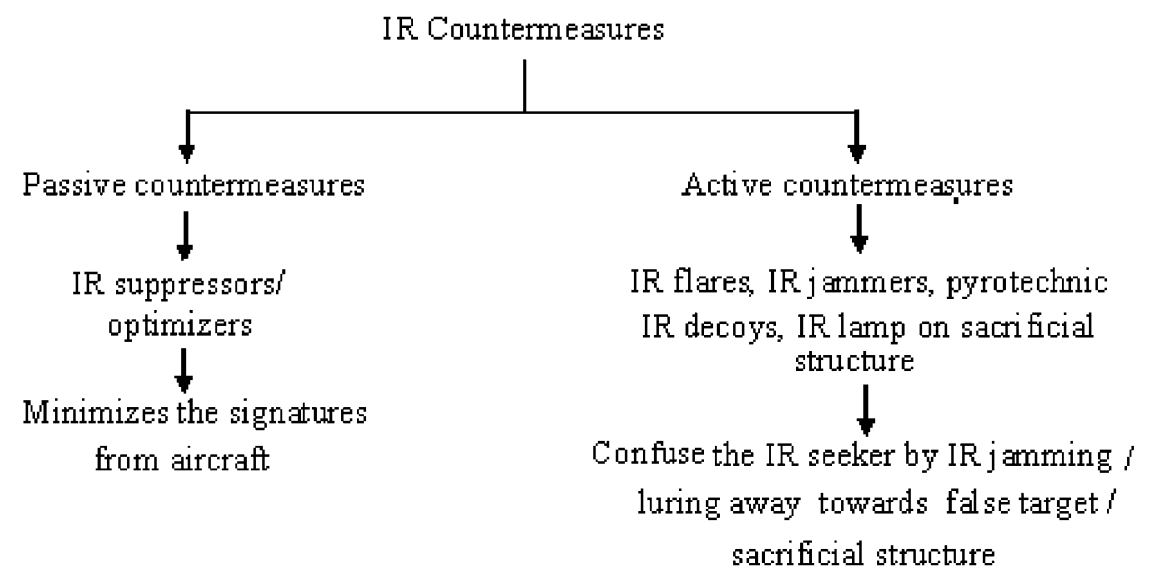

Fig. 14. Classification of IR countermeasures.

they are more susceptible to IR-guided threats. Therefore, IRSS systems were first introduced for helicopters that must operate in hostile environment. Aircraft/helicopters equipped with IRCMs are not necessarily immune to attacks by IR-guided missiles, as counter-countermeasures (CCM) are also being concurrently developed.

\subsection{Passive countermeasures}

Reduction in IRSL by passive countermeasures reduces the susceptibility of aircraft by reducing its $R_{\mathrm{LO}}$. Because, $R_{\mathrm{LO}} \propto \mathrm{IRSL}^{1 / 2}$ (due to the essentially Inverse Square Law dependence), reduction in IRSL by a factor of 10 reduces $R_{\mathrm{LO}}$ by a factor of about 3.16 .

The general objectives of passive countermeasure IRSS systems are as follows: (i) to significantly reduce IRSL from almost all viewing aspects; (ii) maintain engine performance by minimizing backpressure penalty; (iii) minimize weight penalty; (iv) minimize cost and system configuration complexity; (v) minimize external drag; and (vi) while implementing passive IRCMs, other signatures like RCS and acoustic should not increase as a consequence.

The IRSS system consists of any of the following or a combination of the following four techniques/ components:

(i) Masking of hot engine parts; which includes nozzle shape alteration [101-104], jet pipe geometry modification [3,105], and fitment of new assembly [106,107].

(ii) Peak temperature reduction of exhaust gases by enhancing mixing with the surroundings. This can be achieved by altering the nozzle/jet pipe geometry, and by fitment of separate devices in the exhaust system $[16,17]$. The plume IRSL can also be tailored by incorporating and locating a structure that melts/ablates, resulting in mixing of additives into the plume. The structure, which is subjected to melting/ablation can be made from materials like magnesium, aluminium, magnesium-polytetrafluroethylene, carbon, and other energetic solid particles [35]. The plume radiant intensity can be enhanced, reduced, or resonated, by varying the additive material type, composition, density, and ablation/melting rate [35].

(iii) Matching of IRSL by modifying the aircraft skin temperature, to reduce contrast with the surroundings by physical and chemical means. This is achieved by emissivity control [30,33], electric heating of skin [27], liquid evaporative cooling of surfaces, and heat pipe cooling of skin $[28,29]$.

(iv) Reducing the reflectivity of reflecting aircraft surfaces to mitigate the sunshine, skyshine, and earthshine reflections.

\subsubsection{Exhaust system}

In 1977, Hughes helicopter introduced the Black Hole Ocarina (BHO) IRSS system for providing full sphere of protection from heat seeking missiles [106]. The Black Hole system masks the hot engine parts, while the Ocarina system of multiple exhausts dissipates the plume to enhance the mixing process. The BHO system has been installed on OH-6, OH-58, AH-IJ, YAH-64 helicopters and U-21 (turbo-prop) fixed wing aircraft. The installation 
of BHO system on YAH-64 helicopter leads to reduction in IRSL from hot metal parts by $30 \%$ and from plume by $40 \%$ [106]. The IRSS system, DRESBall, originated in the Defence Research Establishment Suffield (DRES), Canada. It consists of a filmcooled outer duct and film-cooled ball that serves as an optical block [107]. The metal surfaces are cooled by convective-film cooling, and the ball blocks the direct view of the exhaust duct. On similar principles, Thompson et al. [3,108] designed and tested the IRSS system, centre body tailpipe (CBT), for the Bell-205 helicopter. It was found that: (i) at the $940 \mathrm{shp}$ operating point, the power loss due to fitment of CBT system is less than $3 \%$; (ii) from side aspect, the IRSL reduction in $3-5 \mu \mathrm{m}$ band is about $70 \%$ and $80 \%$ from $30^{\circ}$ off-tail.

Plume IRSS can also be achieved by engine size reduction, cycle tailoring, plume/aerosol (air) mixing, and nozzle shaping [109]. Injection of carbon particles or water vapour in the plume so that it shields the plume reduces the intensity of IR emissions from the plume substantially [109]. The plume core stretch, its volume, temperature and concentration of IR-radiation participating gases, depend on the bypass ratio (BPR). Decher [67] found that increase in BPR from 0 to 1 rapidly decreases the exhaust gas temperature. However, for $\mathrm{BPR}>1$, the decrease in exhaust gas temperature is much smaller with increase in BPR; hence, $\mathrm{BPR} \sim 1$ gives best results. Trends in thermodynamic cycle parameters which improve the cycle efficiency and lower fuel consumption also lower the heat rejection from engine. Therefore, for given operating point, these trends also lower engine IRSLs $[67,110]$; however, afterburning increases IR emissions by almost 10-folds [67]. A non-axisymmetric nozzle has lesser IR emissions than an axisymmetric nozzle, because the internal engine hot parts are largely masked by the non-axisymmetric nozzle hardware [102]. A non-axisymmetric 2-D wedgeshaped nozzle also enhances the mixing of hot exhaust gases with ambient air, thereby reducing the IRSL of the plume [103,111]. Dix et al. [112] experimentally studied the effect of notched nozzles (illustrated in Fig. 15) on IRSL reduction. They found that a $60^{\circ}$ notched nozzle reduces the length of the hottest part of the plume by $33 \%$, but the reduction in spectral IR-radiance occurs near $4.3 \mu \mathrm{m}$. Notched nozzles facilitate in the radial spreading of the jet and its mixing with ambient air, thereby reducing the plume length. Plume IRSL reduction can also be achieved by enhancing mixing
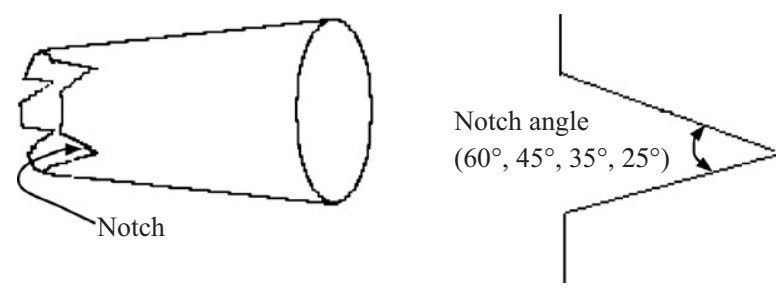

Fig. 15. Schematic sketch of notched nozzle.

of exhaust gases with ambient air by providing the following features at nozzle exit [18]: corrugated surfaces, lobes, scalloped edges, turbulators, and chevrons. Corrugated seals at the nozzle exit, apart from plume IRSL reduction, also reduce the aural signature [113].

\subsubsection{Patented IRSS systems for exhaust. The} IRSS systems that employ the specifically designed device/mixer to discharge the exhaust gases, is patented by almost a dozen researchers. Some designs improve the mixing of exhaust gases with the ambient air (jet dilution) [16,18,20-25]. Other IRSS systems, apart from mixing, relocate the discharge in the downward direction (jet deflection) $[17,26]$. The characteristic features of some patented IRSS systems are now elaborated:

(i) The IRSS system proposed for helicopters by Frawley [16], provides efficient mixing/pumping of the plume with ambient air, irrespective of surrounding cross-flow disturbances. The specially designed mixer entrains the cold atmospheric air, and mixes it with hot exhaust before deflecting in two separate directions. It also mitigates the impingement of the plume on the adjacent structure, thereby avoiding the formation of hot spots on the fuselage.

(ii) Lavergne et al. [17] proposed an IRSS arrangement for helicopters on Nap-Of-theEarth flight, which is used on the Russian helicopter MIL MI-28 HAVOC. This flight is close to the Earth's surface, during which, airspeed and height are adapted to the contours and cover of the ground, for avoiding enemy detection and fire. The IRSS arrangement consists of engine exhaust gases deflected and diluted in the downward direction. In this direction, the exhaust gases attain natural cover provided by the reliefs of terrain, vegetation, and structures; making IR detection and attack difficult from above. This 
arrangement also avoids the heating of the fuselage and main rotor; and in addition, produces a hot spot on ground, which acts as a decoy for attack from above.

(iii) Wollenweber [18] designed an IRSS in which the exhaust gas flow channel is attached to a movable access door. This door can be closed during combat; and when closed, it masks the hot flow channel and hot engine parts.

(iv) Iya and Roe [19] proposed a system for reducing the temperature of the engine by utilizing the fuel for cooling engine and exhaust nozzle, prior to feeding to the combustor.

(v) Steyer et al. [20] proposed a system, which uses an elongated duct for carrying the exhaust gases, which has a baffle to obstruct the view of hot engine parts. The duct and baffle are coated with a combination of high and low emissivity materials, for reducing IR emissions.

(vi) The device proposed by Mathiasson [21] is primarily aimed for stationary plants and military vehicles or vessels; it entrains fresh air for mixing with the hot gases. The atmospheric cold air and diluted hot air are passed through a screen plate after mixing, which also masks the hot parts of the device.

(vii) Siefker et al. [23] proposed an exhaust mixer for gas turbine engines, for reducing the visibility of hot engine parts. A mixer has a number of lobes, each shaped to partially block the engine exhaust; which are curved in a pattern selected to provide a desired degree of blockage. This device enhances the mixing with ambient air; but adds to the weight and complexity, besides loss of thrust.

(viii) Papamoschou [24] proposed a device and method for mixing enhancement of turbofan exhaust gases with ambient air, thereby reducing the plume IR emissions. The system consists of a duct having an outer wall and an inner wall forming a converging-diverging or converging-diverging-converging passage. The flow near the first converging area is equal to or greater than the local speed of sound; and thereafter, the flow has a positive streamwise pressure gradient near the exit.

(ix) Chew et al. [25] proposed a baffled device for enhancing the mixing of hot exhaust gases with the ambient, and for masking the hot engine parts. This baffle module being a retrofit device can be detached whenever IR suppression is not required.

(x) Hammond and Presz Jr. [26] proposed an IRSS system having a multistage mixer/ ejector. At each stage, the hot exhaust gases entrain cold air in the core region of the engine exhaust. This multi-stage mixer device also masks the hot engine parts, maintains engine performance, and thoroughly diffuses the exhaust gases.

\subsubsection{Fuselage IRSS}

Fuselage IR radiance consists of emission by virtue of its temperature, reflected earthshine, skyshine, and sun glint. For a low flying aircraft, even if the rear fuselage emissivity is made zero, the aircraft can still be locked-on by SAM, due to the reflected earthshine in $8-12 \mu \mathrm{m}$ band [57]. In the absence of earthshine, negative contrast with the background sky radiance can be used for aircraft detection and lock-on. Matching of fuselage IR emissions with those of the background is a high potential technique for IR camouflage. The IRSS systems for fuselage can be grouped in two categories: (i) aircraft skin heating/cooling for background matching, and (ii) emissivity optimization for reducing IR signature from the fuselage.

\subsubsection{Aircraft skin heating/cooling. Engelhardt} [27] has patented a system for electrical heating of the upper portion of the fuselage for background matching. The negative IR contrast of the aircraft with respect to the surroundings is minimized, thereby providing IR camouflage when viewed by aircraft flying at higher altitude. However, heating is less often applicable; instead, cooling of the aerodynamically heated fuselage skin especially at high Mach numbers, is more important. Cooling of the skin to a temperature near the ambient air will reduce the aircraft detection range by IR imaging scanners, the quality often desired for the modern battlefield [114]. Heat pipe cooling [28] and liquid evaporative cooling [29] of aircraft skin from inside, were patented as IRSS systems. Also, heating/ cooling of surfaces by thermocouples were patented as an IRSS system [33]. In such systems, the background temperature is sensed and the aircraft skin is heated/cooled to the same temperature, resulting in IR camouflage. The skin is heated or cooled using a thermoelectric module that converts electrical energy into a temperature gradient. By 
application of voltage across these modules, one side of the module becomes hot, and the other side becomes cold. The temperature of the adjacent surface can be controlled by varying the applied voltage.

5.1.2.2. Emissivity optimization. The aircraft IR radiance strongly depends on the emissivity of the radiating surface; which depends on surface temperature, and surface physical and chemical properties. Most methods of IR suppression are associated with performance penalties, e.g. increased drag, additional weight, increased RCS, and increased nozzle back pressure. Emissivity optimization of the aircraft surface is a viable option, which does not impose performance penalties. Mahulikar et al. [57] studied rear fuselage emissivity optimization in the $3-5$ and $8-12 \mu \mathrm{m}$ bands. They found that emissivity reduction from 1.0 to 0.0 reduces peak aircraft spectral lock-on range by almost $100 \%$, in the $8-12 \mu \mathrm{m}$ band. In Fig. 16, it is seen that the lock-on range is more sensitive to emissivity in $8-12 \mu \mathrm{m}$ band, as compared to $3-5 \mu \mathrm{m}$ band. Emissivity can be optimized by physical and chemical treatment of the radiating surfaces.

Friedman's [115] system uses a movable surface structure having predetermined surface characteristics for emissivity control. DeSteese et al. [34] proposed a system where the physical characteristics of surface, cavities, and plurality of cavities, are used to control the emissivity of the surface.

Conway et al. [30] proposed a three-colour camouflage system, consisting of a layer of camouflage material having low, intermediate, and high

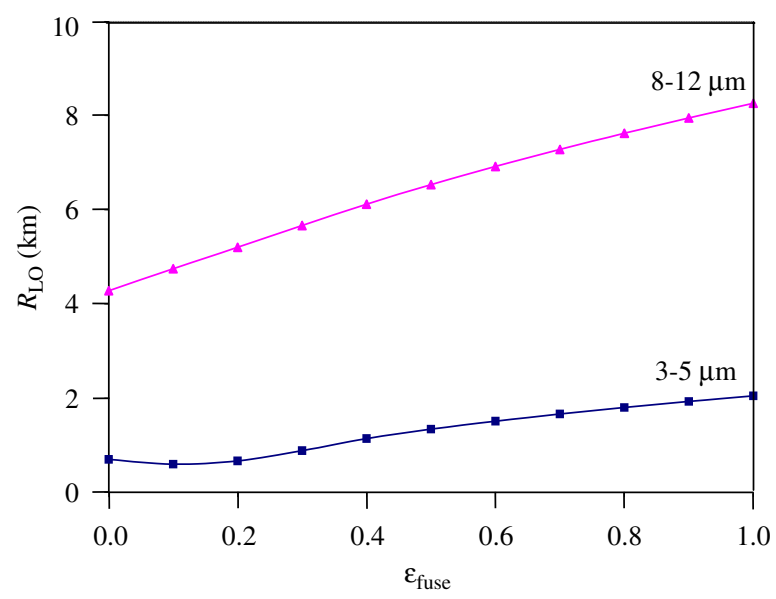

Fig. 16. Variation of peak aircraft lock-on range in two atmospheric windows with rear fuselage emissivity (after [57]). emissivities in the IR spectrum. Surfaces with this layer adopt the colour of the natural background, thereby reducing IR contrast and detection. Engelhardt [116] developed the analytical code Effective Rapid Airframe Suppression Evaluation (ERASE) to evaluate the impact of airframe suppression on lock-on range. The code permits assessing the effect of variations in multiple variables, viz. surface area, temperature, and emissivity, on lock-on range. This code can also be used to perform trade-off analyses associated with IRSS systems. It is ideal for performing design trade-off studies considering airframe shaping, thermal control systems, and diffuse reflectivity/ emissivity control. The trade-off feature of the code is capable of single, double, or triple variable changes to access the synergism of multiple design changes.

\subsubsection{Limitations of IR suppressors}

Passive IRCMs can be incorporated on an aircraft in the initial design or modification stage, or later as retrofits/additives. First generation IR suppressors were simple and aimed to provide optical blockage of hot engine parts. Second generation IR suppressors involve a combination of optical blockage, metal cooling, and exhaust gas cooling; which add more complexity to the system. The major performance penalties associated with incorporation of IR suppressors are discussed below:

(a) Additional weight of IR suppressor: The IRSS systems prior to $\mathrm{BHO}$ included moving parts like blowers. The BHO does not have moving parts, and is lighter by $180 \mathrm{~kg}$ over prior systems [106]. Most passive IR suppressors for helicopters (based on optical blocking and mixing of exhaust gases with ambient) $[4,117]$ add to the weight, as illustrated in Table 4.

(b) Power loss due to bleeding of air and modification of exhaust geometry that increases engine backpressure: Most IR suppressors need airflow to cool heated parts or ejector passages for sucking ambient air, resulting in reduced engine thrust. Such IR suppressors are generally used with TFEs, while their use is restricted on turboprop and turboshaft engines, due to unavailability of excess air. The CBT installed on the Bell-205 (UH-1 H) helicopter results in a back-pressure penalty that leads to a $3 \%$ power loss for the engine operating point corresponding to $940 \mathrm{shp}$ 
Table 4

Weight increase and engine power loss due to IR suppressor installation on helicopter (after [117])

\begin{tabular}{|c|c|c|c|c|c|}
\hline Helicopter & Bell 212/412 & AS 332 & Bell 407 & Bell 205 (UH-1 H) & Mi 17 \\
\hline Weight increase $(\mathrm{kg})$ & 10.88 & 86.18 & 12.24 & 13.6 & 108.86 \\
\hline Power loss & $2 \%$ in hover OGE & $<2 \%$ at $\mathrm{MCP}$ & $<1 \%$ in hover $\mathrm{OGE}$ & $<3 \%$ at $940 \mathrm{SHP}$ & $<3 \%$ at $\mathrm{MCP}$ \\
\hline
\end{tabular}

[108]. Power loss due to IR suppressor installation on helicopter is consolidated in Table 4.

(c) IRSS systems can require major changes to nozzle geometry: High aspect ratio/non-axisymmetric nozzles add to the weight, engine backpressure, drag, and surface area (for faster plume dilution), as compared to axisymmetric nozzles.

(d) Incorporation of IRSS techniques can increase other signatures: High-speed mixing of freestream with jet exhaust increases aural signatures, by increasing the broad-band jet noise.

(e) Incorporation of IRSS techniques increase overall complexity of exhaust system: Fabrication of an enhanced jet mixing system, nozzle, jet-pipe, and its fitment increases cost and decreases reliability due to increased complexity. Cost of a US military program for fitment of countermeasure suites for helicopters was estimated at $\$ 1.6$ million per helicopter [15].

(f) IRSS techniques based on emissivity optimization are less complex and do not involve performance penalties, but they require surface alteration: The efficacy of such systems and implementation on operational aircraft is not yet reported.

Most penalties associated with IRSS systems can be interpreted as follows:

(i) for the same gas generator speed and fuel flow, the IRSS system reduces the power;

(ii) for the same power available for the mission, the IRSS system results in higher fuel flow, higher gas generator speed, and higher exhaust gas temperatures.

In Case (ii), the engine operating point shifts, which increases the temperature of the IRSS system, thereby reducing the IR suppression performance. Because penalties can increase IR signature level and bring down the effectiveness of IRSS system, it is important to keep them as small as possible. But no information is reported that can provide an estimate of the increase in IR signature level due to engine backpressure, weight, and drag penalties of IRSS systems. An analytical model for evaluating net effectiveness of IRSS system is essential to objectively compare several candidates.

\subsection{Active countermeasures}

These countermeasures include IR jammers and IR flares, which serve as decoys by luring away the approaching heat seeking missile. Saturation jammers introduce large amount of IR noise into the threat's tracking system that damages the seeker optics [13]. Smart jammers are either non-directional or directional (DIRCM), and deceive IR trackers by sending false target information [13]. Pyrotechnic IR decoys were developed in the late 1950 s, i.e. about the same time as the availability of IR missiles [118]. The IR flares were used first as active countermeasures against IR seekers in the Vietnam War in the 1960s [119]. These decoys are easy to handle, reliable, and are made of cheap constituents like metal fuels and oxidizers. To imitate the tail-pipe IR spectrum, the decoy flares fired from the rear against revenge-shot IR missiles must radiate strongly in the same band of the IR spectrum. Busting smoke of bronze-copper-lined flakes, bronze flakes, and mixture of flakes with chaff, serve as IR decoys for longer duration [120]. However, the new generation of imaging IR detectors can discriminate IR flare (as point source) and target, making flares ineffective as IRCM. To counter this situation, decoys driven by liquid fuels that produce as large a radiating plume as that of aircraft were proposed. Such decoys use more energetic fuels like tri-ethyl-aluminium, tri-isobutyl-aluminium, di-ethyl-aluminium, etc., which are called as pyrophoric liquids [118]. Air Force Research Laboratory (AFRL)-USA has developed a software tool, Advanced IRCM Assessment Model (AIRSAM), for IRCM assessment. This tool is useful for setting condition for flare detection and application of techniques for CCM [121].

Czarnecki [36] proposed an innovative design consisting of an IR lamp and sacrificial structure, to 
safeguard aircraft from heat seeking missiles. This device provides aircraft vulnerability reduction by coaxing missiles away from crucial aircraft components to the sacrificial structure that uses an IR lamp as decoy [36].

Development of a Missile Approach Warning System (MAWS) against IR-guided missiles is a formidable task. Shoulder Fired Missiles have a typical engagement range of $1-8 \mathrm{~km}$, and a flight time between 2.7 and $13 \mathrm{~s}$ [122]. Therefore, MAWS must be able to detect, track, and declare a missile in less than a second; to enable active countermeasures to operate. A typical MAWS should ideally have the following characteristics: (i) ability to detect the threat at earliest possible time, i.e. at the time of missile launch; (ii) ability to track the threat location as it evolves in time, until missile motor burnout and beyond; (iii) ability to detect the threat from maximum possible launch range; (iv) ability to detect multiple threats; and (v) high signal-to-noise ratio for detecting missile in complex natural and man-made solar and thermal background [123]. There are three technological options available for MAWS [119,124]: (i) Pulse Doppler Radar, (ii) IR detectors (scanning and staring), and (iii) ultraviolet (UV) detectors. The UV detectors are preferred for Helicopter MAWS because background clutter is minimal in the UV spectrum. Therefore, signal processing is simpler and a sensor is not required, which lowers the cost [119].

\subsection{Counter-countermeasures}

CCMs are currently under development to counter the active and passive IRCMs. The CCMs may use new technology that was not envisaged when the countermeasures were originally developed [125]. Some examples of CCM are as follows [125]: (i) increasingly sensitive IR sensors are under development that can also lock-on to airframe, and can detect aircraft equipped with IR suppressors; (ii) imaging seekers, which provide resolution sufficient to distinguish the target from ejected and towed countermeasures; (iii) high-speed temporal processing to identify the time varying characteristics of the target; (iv) high speed to minimize the reaction time available for initiation of countermeasures; (v) high-altitude flight to avoid detection; (vi) high manoeuvrability, to minimize the miss distance from countermeasures; (vii) enhanced low observable features, to avoid target detection; (viii) multiple attack, to overwhelm countermeasures.

\section{Summary and conclusions}

The potent threat from passively guided infrared (IR) homing missiles is articulated, and the resulting concerns regarding operation in a hostile environment are elaborated. Though capabilities of IR technology were known prior to World War I, the initial success of RADAR slowed their development till 1960. Recent developments in IR sensing technology have made it virtually impossible to escape IR-detection. Modern IR imaging systems can differentiate small temperature differences, and are immune to conventional countermeasures that appear as point sources of IR-radiation. Antiaircraft missiles with imaging IR detectors are under development, and are soon likely to find a place in tactical warfare. Therefore, military forces are demanding more stringent IR counter-measures (IRCMs) from future aircraft/helicopters. Survivability against IR-guided threats has found a place in the design stage itself, leading to an upsurge of research on several aspects of IR signature prediction and management. This review summarizes the perspectives that led to various research, design, and developmental activities in this field. The most important points are:

(i) Conventionally, fuselage IR signature was neglected; however, it is now realized that the rear fuselage is the main source of IR signature in $8-12 \mu \mathrm{m}$ band.

(ii) Earlier, the aircraft plume was generally considered as the major source of IR radiation, but research showed that its' significance is restricted to the $4.15-4.20 \mu \mathrm{m}$ band. In particular, the role of atmospheric transmittance of IR in determining this relatively low importance of plume IR radiation is now known.

(iii) The background IR-radiance plays an important role in determining IR signature in the $8-12 \mu \mathrm{m}$ band. The IR signature due to positive contrast decreases and due to negative contrast increases, with increasing background IR-radiance. The atmospheric attenuation reduces IR signature for both, positive and negative contrast.

(iv) The effect of earthshine on rear fuselage IR emissions in the $8-12 \mu \mathrm{m}$ band was identified, and it was shown that earthshine always makes IR-detection of the rear fuselage possible. 
(v) The $\Omega$-subtended by divergent-nozzle is much larger than that subtended by the convergentsection and jet-pipe, and is visible over the complete range of $\phi\left(0^{\circ}-90^{\circ}\right)$. Therefore, considering low IR signature requirement from the rear aspect, use of divergent-nozzle for aircraft engine is not a prudent design.

(vi) The nozzle shape can be modified either by(a) notching/corrugating, (b) changing its aspect ratio, or (c) by specifically designed retrofit devices. These modifications enhance the mixing of exhaust gases with ambient air, thereby reducing the IR signature level especially from the rear aspect.

(vii) Relative to the 'lock-on envelope', the 'lethal envelope' is a more comprehensive parameter for target susceptibility assessment. The introduction of the lethal envelope led to the identification of a threshold IR signature level, above which, IR signature reduction has no effect on target susceptibility.

(viii) Minimizing performance penalties associated with engine backpressure, weight, and drag, due to incorporation of IR suppression features is important. These penalties increase the IR signature level, because the engine operating point must be shifted to a higher temperature for maintaining the output power required for the mission.

(ix) Emissivity alteration/optimization of radiating surfaces are effective tools for IR signature suppression, especially because imposed performance penalties are minimal.

(x) Imaging IR seekers have diminished the effectiveness of IR flares as IRCMs. Directional IR jammers (DIRCM) have emerged as one of the potent active IRCMs.

(xi) The development of a Missile Approach Warning System (MAWS) against IR-guided missiles is a formidable task, considering the dynamics of tactical warfare.

(xii) The emergence of IR CCM has made IR signature management more intricate and exigent.

The IR signatures and associated technologies are significantly shaping the future course of developments in stealth technology and electro-optical (EO) warfare. There is an exigent need to reduce the susceptibility of aircraft against IR-guided missiles, particularly after the growing attacks on civilian aircraft. Modern generation combat aircraft may not survive the human-made hostile environment, if they are deficient in IRCMs.

\subsection{Scope for future research}

Most of the research in IR signature analysis is controlled by military research establishments; hence, there are limited details in the open academic literature. There is a generic need to develop models with improved IR signature prediction capabilities, followed by experimental validation. The capabilities of existing models are far from enabling their utilization in digital IR simulators for real-time evaluation of aircraft susceptibility for decision making in combat. Such developments would provide a reasonably reliable estimate of the effectiveness of IR flares and IR jammers in operation.

The specific areas in which there is a pressing need for future academic research are outlined below:

(i) There is virtually no data in the open literature on measurements of IR signature levels on operational aircraft for various operating conditions and from various angles. Availability of such information would serve as bench-mark cases for academic codes that study the qualitative characteristics and trends.

(ii) Laboratory simulation for IR signature measurement is still under development, as there are issues pertaining to similitude that need to be resolved. Scaling is an issue considering that IR signature level (IRSL) depends on a multitude of parameters that represent several concurrent mechanisms and phenomena.

(iii) There is limited information in the literature on the prediction of IR signature due to miscellaneous sources; e.g. earthshine, sunshine, and skyshine. Their modeling is important for reducing the uncertainties in IRSL prediction.

(iv) No reported model predicts the effect of IRSS system installation penalties on increase in IRSL, due to the shift in engine operating point for maintaining mission power. This deficiency necessitates the coupling of IRSL prediction models with engine off-design performance analyses.

(v) For realistic susceptibility assessment, it is necessary to predict temperature profiles over the entire aircraft skin for different operating conditions. This would enable modelling of the aircraft as a well-resolved distributed source of 
IR radiation, so that actual lock-on and lethal envelopes can be obtained.

(vi) The effectiveness of new IR suppression techniques should be gauged based on the final objective of susceptibility reduction. This necessitates estimation of lock-on and lethal envelopes with and without IRCM, for operating conditions that are typical of human-made hostile environments.

\section{Acknowledgements}

The authors thank the Indian Railways for extending full cooperation for this research investigation, and to CASDE of their Department for the logistics. The authors are grateful to Prof. $\mathrm{Yu}$ Yanwen, Zhejiang University, Hangzhou, PR China, for making available the copy of research paper no. [96]. The authors thank the A. von Humboldt Foundation, Germany, for the rich exposure to research methodology.

\section{References}

[1] Hunter TB. The proliferation of MANPADS. Jane's Intelligence Review 2002; 28 November 〈www.janes.com/ security/international_security/news//jir021128_1_n.shtml $\rangle$.

[2] The MANPADS menace: combating the threat to global aviation from man-portable air defence systems. Bureau of Political-Military Affairs and Bureau of International Security and Non-Proliferation, Washington, DC, September 20, 2005. 〈www.state.gov/t/pm/rls/fs $/ 53558 . h t m\rangle$.

[3] Thompson J, Birk AM, Cunningham M. Design of infrared signature suppressor for the Bell 205 (UH-1H) helicopters, Part I: aerothermal design. In: Seventh CASI propulsion symposium, 1999

[4] Helicopter infrared signature suppression system. A report by W.R. Davis Engineering Ltd., Ottawa, Ontario, January 1993.

[5] Beveridge D. APEC nations agree to limit missile sales. Associated Press 2003; 18 October. 〈www.fas.org/asmp/ campaigns/MANPADS/MANPADS.html\#fnl_tgt $\rangle$.

[6] Hudson Jr RD. Infrared system engineering. 1st ed. New York: Wiley; 1969.

[7] Waldman G, Wootton J. Electro-optical systems performance modelling. 1st ed. Boston: Artech House; 1993.

[8] Kuhn DM. Attack highlights increasing MANPADS threat. Jane's Intelligence Review 2003: 15(2).

[9] Rao GA, Mahulikar SP. Integrated review of stealth technology and its role in airpower. Aeronaut J 2002; 106(1066):629-41.

[10] Ball RE, Atkinson DB. A history of the survivability design of military aircraft. In: Lawless LTC JN Jr, editor. 1995 JTCG/AS air combat survivability symposium, Summer 1995, p. $75-89$.
[11] Aronstein DC, Piccirillo AC. Have Blue and the F-117A: evolution of the stealth fighter, second printing. Reston, VA: AIAA Inc.; 1997.

[12] DeMeis R. F-117A First in stealth. Aerospace America, February 1991, p. 32-6.

[13] Ball RE. The fundamentals of aircraft combat survivability analysis and design. 2nd ed. New York: AIAA Education Series; 2003.

[14] Electronic warfare: DOD should select most cost-effective infrared countermeasures system. US Government report, GAO/NSIAD-98-2, B276171, April 28, 1998.

[15] Electronic warfare: phased approach to infrared upgrades would reduce risk to helicopters. US Government report, GAO/NSIAD-00-171, B-285362, July 27, 2000.

[16] Frawley RC. IR suppressor. US Patent no. 6122907, September 26, 2000.

[17] Lavergne M, Bosqui O, Allemand R. Helicopters equipped with jet dilution/deflection means for the combustion gases. US Patent no. 6123290, September 26, 2000.

[18] Wollenweber GC. Method and apparatus for exhausting gases from gas turbine engines. US Patent no. 6971240 B2, December 6, 2005.

[19] Iya SK, Roe GM. System and method for controlling the temperature and infrared signature of an engine. US Patent no. 7013636 B2, March 21, 2006.

[20] Steyer W, Kieffer C.M., Jasany J.M., Hoffman J. Method and apparatus for suppressing infrared signatures. US Patent no. 6988674 B2, January 6, 2006.

[21] Mathiasson U. Device for reducing the signature of hot exhausting gases. US Patent no. 6937181 B2, August 30, 2005.

[22] Gustafsson T, Olsson O. Exhaust discharge system with low IR signature. US Patent no. 6385968 B1, May 14, 2002.

[23] Siefker RG, Baily RV, Baker VD, Khalid SA, Loebig JC. Exhaust mixer and apparatus using same. US Patent no. 6606854 B1, August 19, 2003.

[24] Papamoschou D. Mixing enhancement using axial flow. US Patent no. 6666016 B2, December 23, 2003.

[25] Chew T, Moore CC, Harrold MC. Removable baffle infrared suppressor. US Patent no. 6253540 B1, July 3, 2001.

[26] Hammond MH, Presz Jr WM. Multi-stage mixer/ejector for suppressing infrared radiation. US Patent no. 6016651, January 25, 2000

[27] Engelhardt M. Apparatus and method for electrical heating of aircraft skin for background matching. US Patent no. 4801113, January 31, 1989.

[28] Engelhardt M. Heat pipe cooling of aircraft skin for infrared radiation matching. US Patent no. 6435454 B1, August 20, 2002.

[29] Miller RC, Seemann RJ. Infrared signature reduction of aerodynamic surfaces. US Patent no. 4991797, February 12, 1991.

[30] Conway TG, McClean RG, Walker GW. Three color infrared camouflage system. US Patent no. 5077101, December 31, 1991.

[31] Stevens WC, Sturm EA. Infrared radiation-interaction article and method of generating a transient infrared signature response. US Patent no. 5571621, November 5, 1996.

[32] Leupolz A, Scherber W, Rothmund W. Infrared camouflage device. US Patent no. 6613420 B1, September 2, 2003. 
[33] Reynolds RF, Kinsell MJ. Thermal and visual camouflage system. US Patent no. 6338292 B1, January 15, 2002.

[34] DeSteese JG, Antoniak ZI, White M, Peters TJ. Structure and method for controlling the thermal emissivity of a radiating object. US Patent no. 6713774 B2, March 30, 2004.

[35] Vickery CA, Mason JN, Kruse WD, Olmos M. Rocket exhaust plume signature tailoring. US Patent no. 6684622 B2, February 3, 2004.

[36] Czarnecki GJ. Aircraft missile-hit survivability using infrared lamp and sacrificial support structure. US Patent no. 6267039 B1, July 31, 2001.

[37] Beier K. Infrared radiation model for aircraft and re-entry vehicle. In: Proceedings of SPIE-The International Society for Optical Engineering: infrared technologyXIV, vol. 972. Bellingham, WA, USA: SPIE (Society of Photo-Optical Instrumentation Engineers); 1988. p. 363-74.

[38] Burch DE, Gryvnak DA. Laboratory measurement of the infrared absorption by $\mathrm{H}_{2} \mathrm{O}$ and $\mathrm{CO}_{2}$ in regions of weak absorption. In: Proceedings of SPIE-The International Society for Optical Engineering: optical properties of the atmosphere, vol. 142. Bellingham, WA, USA: SPIE; 1978. p. 16-24.

[39] Regelson E. Impact of IR devices on aircraft design trends. Astronaut Aeronaut 1967;5:60-4.

[40] Mahulikar SP, Sane SK, Gaitonde UN, Marathe AG. Numerical studies of infrared signature levels of complete aircraft. Aeronaut J 2001;105(1046):185-92.

[41] Sizov FF. Infrared detectors: outlook and means. Semicond Phys Quant Electron Optoelectron 2000;3(1):52-8.

[42] Sully PR, VanDam D, Bird J, Luisi D. Development of a tactical helicopter infrared signature suppression (IRSS) system. In: Proceedings of AGARD-FVP conference, 96054-001. Paper no. 12, 1996.

[43] Choi KK. QWIP technology: advances and prospects. In: Blood P, Osinski M, Arakawa Y, editors. Proceedings of SPIE-The International Society for Optical Engineering: physics and simulation of optoelectronic devices-X, vol. 4646. Bellingham, WA, USA: SPIE; 2002. p. 79-93.

[44] Choi KK. Corrugated quantum well infrared photodetectors and arrays. Int $\mathbf{J}$ High Speed Electron Systems 2002;12(3):715-59.

[45] Chen CJ, Choi KK, Chang WH, Tsui DC. Two-color corrugated quantum-well infrared photodetector for remote temperature sensing. Appl Phys Lett 1998;72(1): 7-9.

[46] Bell WA, Glasgow BB. Impact of advances in imaging infrared detectors on anti-aircraft missile performance. In: Holst GC, editor. Proceedings of SPIE-The International Society for Optical Engineering, Infrared imaging systems: design, analysis, modelling, and testing-X, vol. 3701 . Bellingham, WA, USA: SPIE; 1999. p. 244-53.

[47] Glasgow BB, Bell WA. Future of anti-aircraft imaging infrared seeker missile threats. In: IEEE proceedings of aerospace applications conference (Cat. no.99TH8403), vol. 4. Piscataway, NJ, USA: IEEE; 1999. p. 457-65.

[48] Eisner L, Bell EE, Young J, Oetjen RA. Spectral radiance of sky and terrain at wavelengths between 1 and $20 \mu \mathrm{m}$ III. Terrain measurements. J Opt Soc Am 1962;52(2):201-9.

[49] Berger XA. Simple model for computing the spectral radiance of clear skies. Solar Energy 1988;40(4):321-33.
[50] Kneizys F.X., Shettle E.P., Abreu L.W., Chetwynd J.H, Anderson G.P. Lowtran-7 computer code user's manual. Air Force Geophysics Laboratory Hanscom AFB MA, AFGL-TR-88-0177, 1988.

[51] Rao GA, Mahulikar SP. Effect of atmospheric transmission and radiance on aircraft infrared signatures. J Aircraft 2005;42(4):1046-54.

[52] McGlynn JD, Auerbach SP. IR signature prediction errors for skin-heated aerial targets. In: Proceedings of SPIEThe International Society for Optical Engineering, Targets and backgrounds: characterization and representationIII, vol. 3062. Bellingham, WA, USA: SPIE; 1997. p. $22-30$.

[53] Berdahl P, Fromberg R. The thermal radiance of clear skies. Solar Energy 1982;29(4):299-314.

[54] Berger X, Bathiebo J. From spectral clear sky emissivity to total clear sky emissivity. Solar Wind Technol 1989;6(5): 551-6.

[55] Bliss RW. Atmospheric radiation near the surface of the ground: a summary for engineers. Solar Energy 1961;5: 103-20.

[56] Bell EE, Eisner L, Young J, Oetjen RA. Spectral radiance of sky and terrain at wavelengths between 1 and $20 \mu \mathrm{m}$ II. Sky measurements. J Opt Soc Am 1960;50(12):1313-20.

[57] Mahulikar SP, Rao GA, Kolhe PS. Infrared signatures of low-flying aircraft and their rear fuselage skin's emissivity optimization. J Aircraft 2006;43(1):226-32.

[58] Jacobs P. Review of the technology and research in the area of infrared signature of targets and backgrounds. In: Proceedings of SPIE - The International Society for Optical Engineering: characterization, propagation, and simulation of infrared scenes, vol. 1311. Bellingham, WA, USA: SPIE; 1990. p. 80-94.

[59] Hipps LE. The infrared emissivities of soil and Artemisia tridentata and subsequent temperature corrections in a shrub-steppe ecosystem. Remote Sensing Environ 1989;27(3):337-42.

[60] Foster WD, Register HI. Collection and simulation of spatial infrared signatures of military jet aircraft. AIAA paper no. 1981-2494. Reston, VA, USA: AIAA Inc.; 1981.

[61] Heragu SS, Rao KVL, Raghunandan BN. Generalized model for infrared perception from an engine exhaust. J Thermophys Heat Transfer 2002;16(1):68-76.

[62] Varney GE. Infrared signature measurement techniques and simulation methods for aircraft survivability. AIAA paper no. AIAA-79-1186. Reston, VA, USA: AIAA Inc.; 1979.

[63] Howe D. Introduction to the basic technology of stealth aircraft: Part 1-basic considerations and aircraft self emitted signals (passive considerations). ASME J Eng Gas Turbines Power 1991;113(75):75-9.

[64] Mahulikar SP. Prediction of engine casing temperature of fighter aircraft for infrared signature studies. In: Proceedings of SAE's aerospace Atlantic conference, SAE paper no. 920961. Warrendale, PA, USA: SAE Inc.; 1992. p. $1-10$.

[65] Mahulikar SP, Kolhe PS, Rao GA. Skin temperature prediction of aircraft rear fuselage with multi-mode thermal model. J Thermophys Heat Transfer 2005;19(1): 114-24.

[66] Mahulikar SP, Potnuru SK, Kolhe PS. Analytical estimation of solid angle subtended by complex well-resolved 
surfaces for infrared detection studies. Appl Opt 2007;46(22):4991-8.

[67] Decher R. Infrared emissions from turbofans with high aspect ratio nozzles. J Aircraft 1981;18(12):1025-31.

[68] Krishnamoorthy V, Pai BR. Aerothermodynamics and infrared emission characteristics of simulated aeroengine jet plumes. Report by National Aerospace Laboratories, Bangalore, India. Document no. PD PR 9113, July 1991.

[69] Lefebvre AH. Flame radiation in gas turbine combustion chambers. Int J Heat Mass Transfer 1984;27(9):1493-510.

[70] Chu CW, Der J, Wun W. Simple two-dimensional nozzle plume model for infrared analysis. J Aircraft 1981;18(12): 1038-43.

[71] Heragu SS, Rao KVL. Prediction of radiative transfer from potential core of a hot jet. J Thermophys Heat Transfer 1994;8(2):368-70.

[72] Nelson HF, Tucker EO. Infrared emission from the engine exhaust plumes. AIAA paper no. AIAA-1986-465. Reston, VA, USA: AIAA Inc.; 1986. p. 8.

[73] Bakker E.J, Fair M.L., Schleijpen H.M.A. Modelling multi spectral imagery data with NIRATAM v3.1 and NPLUME v1.6. In: Proceedings of SPIE-The International Society for Optical Engineering, Targets and backgrounds: characterization and representation-V, vol. 3699. Bellingham, WA, USA: SPIE; 1999. p. 80-91.

[74] Ibgui L, Hartmann JM. An optimized line by line code for plume signature calculations - I: model and data. J Quant Spectrosc Radiat Transfer 2002;75(3):273-95.

[75] Ibgui L, Valentin A, Merienne MF, Jenouvrier A, Lux JP, Le Doucen R, et al. An optimized line-by-line code for plume signature calculations, II: comparisons with measurements. J Quant Spectrosc Radiat Transfer 2002;74(4):401-15.

[76] Soufiani A, Taine J. High temperature gas radiative property parameters of statistical narrow-band model for $\mathrm{H}_{2} \mathrm{O}, \mathrm{CO}_{2}$ and $\mathrm{CO}$, and correlated- $\mathrm{K}$ model for $\mathrm{H}_{2} \mathrm{O}$ and $\mathrm{CO}_{2}$. Int J Heat Mass Transfer 1997;40(4):987-91.

[77] Hewitt CR, Black WZ. Effect of line Doppler shift on plume infrared signatures. J Thermophys Heat Transfer 1995;9(4):636-43.

[78] Rao GA, Mahulikar SP. Aircraft powerplant and plume infrared signature modelling and analysis. In: Meeting papers of 43rd AIAA Aerospace sciences meeting and exhibits. AIAA paper no. AIAA-2005-0221. Reston, VA, USA: AIAA Inc.; 2005. p. 1397-407.

[79] Mahulikar SP, Rao GA, Sane SK, Marathe AG. Aircraft plume infrared signature in nonafterburning mode. J Thermophys Heat Transfer 2005;19(3):413-5.

[80] Cogliandro S, Castelli P. Plume infrared signature measurements and comparison with a theoretical model. In: Proceedings of SPIE-The International Society for Optical Engineering: infrared technology-XII, vol. 658. Bellingham, WA, USA: SPIE; 1986. p. 73-9.

[81] Ludwig CB, Klier AM, Malkmus W, Adams M, Newby, H. Infrared radiation from rocket plumes. In: Proceedings of SPIE-The International Society for Optical Engineering: infrared technology-XVI, vol. 1341. Bellingham, WA, USA: SPIE; 1990. p. 410-22.

[82] Nelson HF. Evaluation of rocket plume signature uncertainties. J Spacecraft Rockets 1987;24(6):546-51.

[83] Nelson HF. Influence of particulates on infrared emission from tactical rocket exhausts. J Spacecraft Rockets 1984; 21(5):425-32.
[84] Victor AC. Calculations of rocket plume afterburning coupled to reacting base recirculation regions. J Spacecraft Rockets 1977;14(9):534-8.

[85] Miller E. Prediction of the visible signature of solid rocket plumes. J Spacecraft Rockets 1990;27(1):82-4.

[86] Ajdari E, Gutmark E, Parr TP, Wilson KJ, Schadow KC. Thermal imaging of afterburning plumes. J Propulsion Power 1991;7(6):873-8.

[87] Nelson HF. Influence of scattering on infrared signatures of rocket plumes. J Spacecraft Rockets 1984;21(5): 508-10.

[88] Avital G, Cohen Y, Gamss L, Kanelbaum Y, Macales J, Trieman B, et al. Experimental and computational study of infrared emission from underexpanded rocket exhaust plumes. J Thermophys Heat Transfer 2001;15(1-4):377-83.

[89] Vaitekunas DA, Fraedrich DS. Validation of the NATOstandard ship signature model (SHIPIR). In: Proceedings of SPIE-The International Society for Optical Engineering, Targets and backgrounds: characterization and representation $-\mathrm{V}$, vol. 3699. Bellingham, WA, USA: SPIE; 1999. p. 103-13.

[90] Sanders JS, Johnson KR, Curran AR, Rynes PL. Ground target infrared signature modeling with the Multi-Service Electro-optic Signature (MuSES) code. In: Proceedings of SPIE-The International Society for Optical Engineering, Targets and backgrounds - vi: characterization, visualization, and the detection process, vol. 4029. Bellingham, WA, USA: SPIE; 2000. p. 197-204.

[91] Gonda T.G., Gerhart G.R. High-resolution infrared signature modelling: a US army perspective. In: Proceedings of SPIE-The International Society for Optical Engineering, Infrared detectors and focal plane arraysII, vol. 1685. Bellingham, WA, USA: SPIE; 1992. p. 92-102.

[92] Noah MA, Kristl J, Schroeder JW, Sandford, BP. NIRATAM-NATO Infrared Air Target Model. In: Proceedings of SPIE - The International Society for Optical Engineering: surveillance technologies, vol. 1479. Bellingham, WA, USA: SPIE; 1991. p. 275-82.

[93] Bishop GJ, Caola M.J, Geatches RM, Roberts NC. SIRUS spectral signature analysis code. In: Proceedings of SPIEThe International Society for Optical Engineering, Targets and backgrounds-IX: characterization and representation, vol. 5075. Bellingham, WA, USA: SPIE; 2003. p. $259-69$.

[94] Iannarilli Jr FJ, Wohlers MR. End-to-end scenariogenerating model for IRST performance analysis. In: Proceedings of SPIE - The International Society for Optical Engineering: signal and data processing of small targets, vol. 1481. Bellingham, WA, USA: SPIE; 1991. p. 187-97.

[95] DiMarco JS. Closed loop modelling of imaging infrared missiles. Proceedings of SPIE-The International Society for Optical Engineering, Targets and backgrounds: characterization and representation-IV, vol. 3375. Bellingham, WA, USA: SPIE; 1998. p. 221-9.

[96] Yu Y, Liu Y. Generation of realistic infrared image for moving objects. Int J Infrared Millimeter Waves 2004; 25(7):1087-97.

[97] Yu W, Tu H, Wang Z, Wang Y, Peng Q. An infrared image synthesis model for high-speed targets. Int $\mathrm{J}$ Infrared Millimeter Waves 2002;23(12):1743-51. 
[98] Sundberg RL, Gruninger J, Nosek M, Burks J, Fontaine E. Quick image display (QUID) model for rapid real-time imagery and spectral signatures. Proceedings of SPIE-The International Society for Optical Engineering, SPIE technologies for synthetic environments: hardware-in-the-loop testing, ii-proceedings, vol. 3084. Bellingham, WA, USA: SPIE; 1997. p. 272-81.

[99] Bell W.A., Glasgow B.B. On the next generation of imaging infrared seekers for anti-aircraft missiles. In: Proceedings of SPIE - The International Society for Optical Engineering, Infrared imaging systems: design, analysis, modeling, and testing-IX, vol. 3377. Bellingham, WA, USA: SPIE; 1998. p. $220-30$.

[100] Rao GA, Mahulikar SP. New criterion for aircraft susceptibility to infrared homing missiles. Aerospace Sci Technol 2005;9(8):701-12.

[101] Wu C, Farokhi S, Taghavi R. Computational study of advanced exhaust system transition ducts with experimental validation. J Propulsion Power 1993;9(3):437-42.

[102] Banken G.J., Cornette W.M., Gleason K.M., Keith M. Investigation of infrared characteristics of three generic nozzle concepts. In: Proceedings of AIAA/SAE/ASME 16th joint propulsion conference, AIAA paper no. 80-1160. Reston, VA, USA: AIAA Inc.; 1980. p. 11.

[103] Capone FJ, Gowadia NS, Wooten WH. Performance characteristics of nonaxisymmetric nozzles installed on an F-18 propulsion model. J Aircraft 1980;17(6):387-92.

[104] Miller E, Protopapas J. Nozzle design and integration in an advanced supersonic fighter. AIAA paper no. AIAA-791813. Reston, VA, USA: AIAA Inc.; 1979.

[105] Singh VP, Mahulikar SP, Raja AT. Infrared signature suppression system for marine gas turbine exhaust. J Mar Eng 1995;33:42-7.

[106] Barlow B, Petach A. Advanced design of infrared suppressor for turboshaft engines, In: Proceedings of 33rd annual national forum of the American Helicopter Society, Washington, DC, Paper no. 77, 1977.

[107] Birk AM, VanDam D. Infrared signature suppression for marine gas turbines: Comparison of sea trial and model test results for the DRES Ball IRSS system. J Eng Gas Turbine Power 1994;116(1):75-81.

[108] Thompson J., Gubbels A.W, Barry B., Birk A.M. Design of an infrared signature suppression for the Bell 205 (UH-1H) helicopter, Part-II: engine \& flight testing. In: Proceedings of 11 th CASI aerodynamics symposium, 2001.

[109] Wang J, Gao J, Wang W, Wang J, Xie J. Aircraft plume signature suppression and stealth. Proceedings of SPIEThe International Society for Optical Engineering, Infrared components and their applications, vol. 5640. Bellingham, WA, USA: SPIE; 2005. p. 579-86.

[110] Wallin M, Gronstedt T, Hall U. A study of engine configurations for a low-signature reconnaissance UAV. In: Proceedings of XVI international symposium on air breathing engines, Cleveland, Ohio. Paper no. AIAA \& ISABE-2003-1093. Reston, VA, USA: AIAA Inc.; 2003.

[111] Lamb M, Taylor JG, Frassinelli MC. Static internal performance of a two-dimensional convergent-divergent nozzle with external shelf. NASA Technical Memorandum 4719, Langley Research Centre, September 1996.

[112] Dix J, Saddington AJ, Knowles K, Richardson MA. Infrared signature reduction study on a small-scale jet engine. Aeronaut J 2005;109(1092):83-8.

[113] Seiner JM, Ukeiley LS, Jansen BJ, Kannepalli, C, Dash, S. Noise reduction technology for F/A-18 E/F aircraft. In: Collection of technical papers-10th AIAA/CEAS aeroacoustics conference, vol. 3. AIAA paper no. 2004-2972, 2004, p. 1938-50.

[114] Pruyn RR, Windolph GW. Survivability tradeoff considerations for future military observation helicopters. J Am Helicopter Soc 1979;24(2):4-9.

[115] Friedman MH. Passive control of emissivity, colour and camouflage. US Patent no. 5734495, March 31, 1998.

[116] Engelhardt M. Effective rapid airframe suppression evaluation (ERASE). In: Proceedings of the SPIE-The International Society for Optical Engineering, Infrared imaging systems: design, analysis, modeling, and testing - IV, vol. 1969. Bellingham, WA, USA: SPIE; 1993. p. 128-38.

[117] W.R. Davis Engineering Ltd., Ottawa, Canada; Newsletter, April 2005, issue 12.

[118] Koch EC. Review on pyrotechnic aerial infrared decoys. Propellants Explosives Pyrotech 2001;26(1):3-11.

[119] Heikell J. Electronic warfare self-protection of battlefield helicopters: a holistic view. PhD thesis, Helsinki University of Technology, Finland, March 2005.

[120] Singh A, Avachat SG, Joshi SA, Singh H. Evaluation of pyrotechnic smoke for anti-infrared and anti-laser roles. Propellants Explosives Pyrotech 1995;20(1):16.

[121] Cohen R, Forrai D, Maier J. Tool for infrared countermeasures assessment. In: IEEE Proceedings of national aerospace and electronics conference NAECON, 2000, p. 110-7.

[122] Montgomery JB, Sanderson RB, Baxley FO. A tactical mid-infrared testbed. In: Proceedings of SPIE-The International Society for Optical Engineering, Targets and backgrounds - VI: characterization, visualization, and the detection process, vol. 4029. Bellingham, WA, USA: SPIE; 2002. p. 93-101.

[123] Peli T, Monsen P, Stahl R, Pauli M, McCamey K. Signal processing improvements for infrared missile warning sensors. In: IEEE Proceedings of national aerospace and electronics conference NAECON, vol. 2, 1997, p. 1052-64.

[124] Sanderson RB. Infrared missile warning sensors. In: IEEE Proceedings of national aerospace and electronics conference NAECON, vol. 2, 1996, p. 777-81.

[125] Fleeman EL. Tactical missile design. 2nd ed. New York: AIAA Education Series; 2006. 